DIW BERLIN

Discussion

Papers
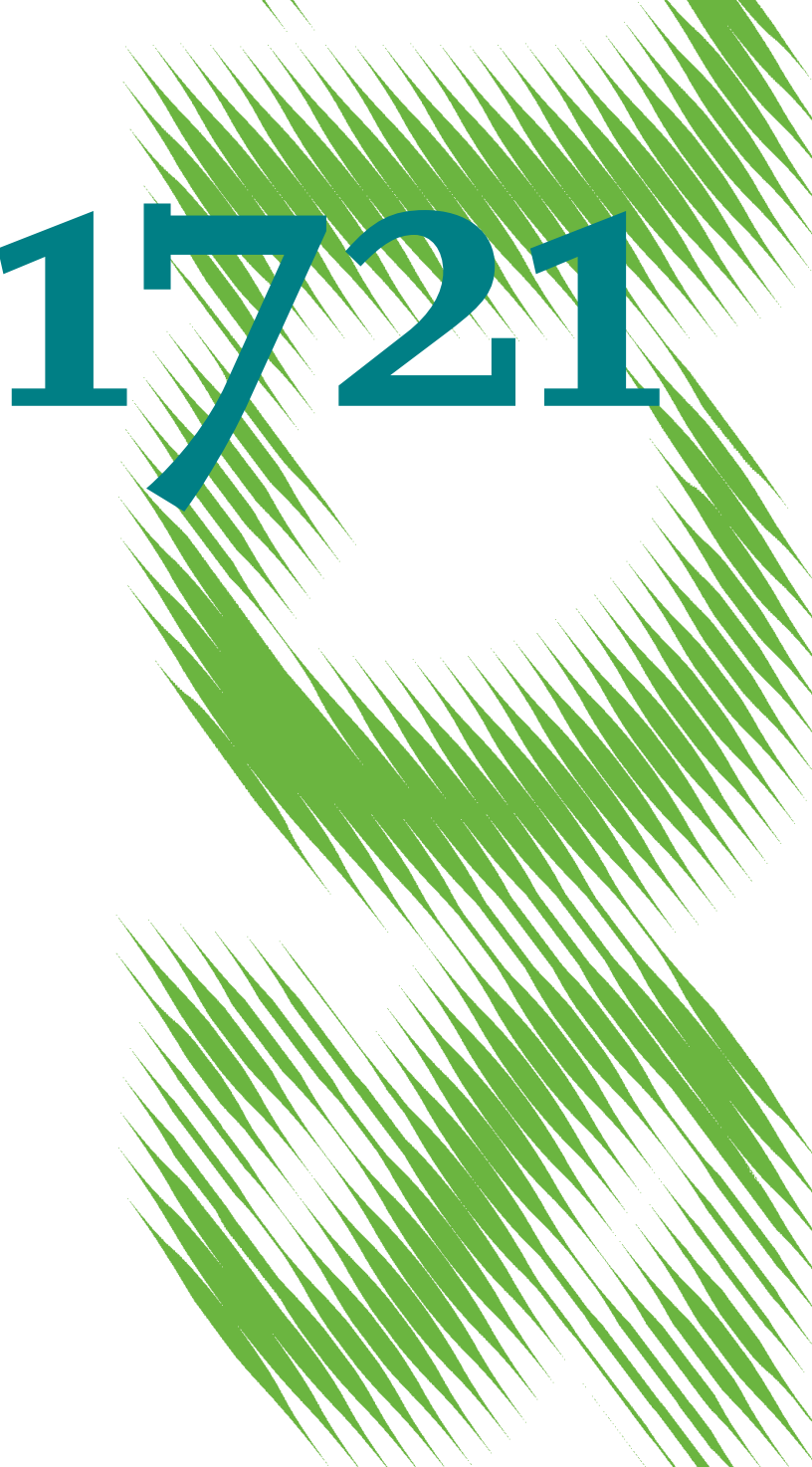

Inflation Targeting as a Shock Absorber 
Opinions expressed in this paper are those of the author(s) and do not necessarily reflect views of the institute.

IMPRESSUM

(C) DIW Berlin, 2018

DIW Berlin

German Institute for Economic Research

Mohrenstr. 58

10117 Berlin

Tel. +49 (30) $89789-0$

Fax +49 (30) $89789-200$

http://www.diw.de

ISSN electronic edition 1619-4535

Papers can be downloaded free of charge from the DIW Berlin website:

http://www.diw.de/discussionpapers

Discussion Papers of DIW Berlin are indexed in RePEc and SSRN:

http://ideas.repec.org/s/diw/diwwpp.html

http://www.ssrn.com/link/DIW-Berlin-German-Inst-Econ-Res.html 


\title{
Inflation Targeting as a Shock Absorber
}

\author{
Marcel Fratzscher§ \\ (DIW Berlin, Humboldt-University Berlin, CEPR) \\ Christoph Grosse Steffen ${ }^{+}$ \\ (Banque de France) \\ Malte Rieth ${ }^{\ddagger}$ \\ (DIW Berlin)
}

FEBRUARY 2018

We study the characteristics of inflation targeting as a shock absorber, using quarterly data for a large panel of countries. To overcome an endogeneity problem between monetary regimes and the likelihood of crises, we propose to study large natural disasters. We find that inflation targeting improves macroeconomic performance following such exogenous shocks. It lowers inflation, raises output growth, and reduces inflation and growth variability compared to alternative monetary regimes. This performance is mostly due to a different response of monetary policy and fiscal policy under inflation targeting. Finally, we show that only hard but not soft targeting reaps the fruits: deeds, not words, matter for successful monetary stabilization.

Key words: Monetary Policy, Central Banks, Monetary Regimes, Dynamic Effects.

JEL classification: E42, E52, E58.

\footnotetext{
*Acknowledgements. We are thankful to Philippe Andrade, Agnès Bénassy-Quéré, Kerstin Bernoth, Fabio Canova, Michael Burda, Boris Hofmann, Athanasios Orphanides, Guillaume Plantin, Christian Proano, Federico Ravenna, Francisco Ruge-Murcia, Willi Semmler, Lutz Weinke and to participants of seminars and conferences at Computing in Economics and Finance New York USA 2017, International Association of Applied Economics Sapporo Japan 2017, Verein für Socialpolitik Vienna 2017, European Economic Association Lisbon 2017, Banque de France, DIW Berlin, and Humboldt University Berlin for useful comments and suggestions. The views expressed in this paper reflect the opinion of the authors and do not necessarily express the views of the Banque de France or the Eurosystem.

$\S$ DIW Berlin, Mohrenstraße 58, 10117 Berlin, Germany. Email: mfratzscher@ diw.de

${ }^{+}$Banque de France, 31 rue Croix des Petits-Champs, 75001 Paris, France. Email: christoph.grossesteffen@banque-france.fr

‡ DIW Berlin, Mohrenstraße 58, 10117 Berlin, Germany. Email: mrieth@ diw.de
} 


\section{Introduction}

Inflation targeting has become a dominant framework for monetary policy over the last two decades. It has been praised for its success in bringing down inflation and raising credibility and accountability of policymakers (Bernanke and Mishkin, 1997; Ball, 2010). Its popularity is reflected in an increasing number of countries adopting inflation targeting (IT). The global financial crisis, however, has dramatically changed the perception of IT as an optimal framework for achieving macroeconomic stability, in particular at times when the economy is confronted with large real or financial shocks. It has been argued that IT, by focusing narrowly on inflation, may contribute to a build-up of financial instability (Taylor, 2007; Frankel, 2012), lead central banks to neglect other objectives, such as employment (Stiglitz, 2008), and constrain monetary authorities in dealing with deep recessions (Borio, 2014). As a result, scholars and policymakers call for a refinement of the IT framework to allow for more flexibility(Svensson, 2009).

Many studies have analyzed whether inflation targeting affects economic performance, though no clear-cut consensus has emerged. The focus of most papers in the literature has been on the performance of IT during the relatively good times of the 1990s and till the beginning of the 2008 global financial crisis. During those two decades of the "great moderation", with declining and low inflation rates amid strong economic growth, only few countries operating under IT experienced a deep economic or financial crisis. A different and arguably at least equally important question is whether IT helps countries and their central banks in dealing with crises, that is, whether it allows stabilizing inflation and output in response to large adverse shocks.

This paper focuses on this question and analyzes whether countries operating under IT have a better macroeconomic performance in response to large adverse shocks than those with non-IT regimes. Thereby, we empirically respond to the question whether IT is a perpetrator, bystander or savior in the wake of a crisis (Reichlin and Baldwin, 2013). We limit the analysis to the effects of natural disasters, such as earthquakes or windstorms, as these are the most exogenous large adverse shocks that can be identified and as they have been shown to have a large impact on the macro-economy (Noy, 2009; Felbermayr and Gröschl, 2014). Natural disasters have a direct negative effect through the destruction of physical capital and durable consumption goods. The analysis can be extended to include other types of shocks, such as financial shocks, though this would entail the risk of endogeneity to the monetary regime. At the same time share natural 
disaster shocks patterns with shocks to the depreciation rate of capital that have been used for the analysis of financial crises (Liu et al., 2011).

Natural disasters can be considered exogenous to the choice of the monetary regime because they are largely unpredictable and not caused by economic conditions. These features allow us to identify the conditional effects of IT using relatively weak and verifiable assumptions about the distribution of the unobserved factors that determine macroeconomic outcomes and about the systematic relation between natural disasters and monetary regimes. In terms of the treatment literature, we assume that conditioned on country characteristics the "treatment" in form of a natural disaster is random, but instead of focusing on the effects of the treatment, we study whether alternative monetary regimes imply different responses to the treatment. To obtain a measure of such shocks, we use the reported insurance damage from the EM-DAT dataset, which documents natural disasters globally. We match them with quarterly macroeconomic data for 76 countries over the period 1970Q1-2015Q4. We then estimate a set of dynamic panel models to trace out the responses of key variables.

We find that disaster shocks are contractionary and inflationary on impact, followed by a short-lived boom in consumption and investment activity. The empirical patterns resemble adverse supply shocks in a New Keynesian model due to a destruction of physical capital and a decline in productivity (Keen and Pakko, 2011). The interpretation as an adverse supply shock is in line with microeconomic evidence hinting toward economic disruptions that also cause indirect losses. Inoue and Todo (2017) show that the Great East Japan earthquake of 2011 was propagated via supply chain disruptions to other regions. The substitution of production inputs poses a drag on firm productivity. The subsequent investment boom we find in the data can be understood through the lens of the Solow (1956) model as catch-up growth.

We document important differences in the dynamic responses of countries under IT (targeters) and under alternative monetary regimes (non-inflation targeters) to the shocks. Targeters perform significantly better regarding both the level and the volatility of output and prices. While GDP drops immediately under both regimes, the initial decline is smaller under IT and the subsequent recovery is stronger and faster. Moreover, consumer prices increase significantly less for targeters. These dynamics are reflected in significant differences across monetary regimes in average GDP growth and inflation following large shocks. The mean quarterly growth rate is 0.2 percentage points higher 
under IT, and average inflation is 0.4 percentage points lower. Moreover, there is robust evidence that inflation targeters are more successful in stabilizing both output growth and inflation. The standard deviation of both variables following a natural disaster is only half of the size as under alternative monetary regimes.

The main aim of the paper is to provide these stylized facts and we are agnostic about the precise channels leading to the main results. Nevertheless, we also provide evidence on the potential mechanisms through which IT affects the adjustment processes. The results suggest that targeters rely on a different monetary-fiscal policy mix, they profit from reduced macroeconomic volatility and lower financial frictions, and their external sector provides a better buffer.

Most strikingly, targeting central banks tighten monetary policy more or loosen it less following the adverse shock to stabilize inflation, while fiscal policy is accommodating. We interpret these findings in the light of a policy coordinating role of IT. A higher coefficient on inflation in the loss function of central banks enforces a sound fiscal position which, in turn, prevents from pro-cyclical public spending in the wake of large disasters. The existence of cross-effects between IT and fiscal policy was documented by Combes et al (2017). Our findings depict that they also shape the policy mix in response to large disaster shocks. Importantly, we extensively control for the institutional quality, which is often held responsible for pro-cyclical fiscal policy in middle-income countries (Frankel et al. 2013), as well as for fiscal rules and alternative financing capacities of countries. In contrast, non-targeting monetary authorities tend to ease monetary policy more aggressively and persistently in an effort to stabilize output, while fiscal policy is contractionary. The adverse effects of private credit risk and term premia reduce the effectiveness of monetary policy for non-inflation targeters such that overall this policy mix induces lower output growth, higher inflation, and more volatility.

Finally, we find that only hard targeters perform better. Countries which have introduced inflation targeting, but deviate from their target for a prolonged period of time, do not reap the fruits. This difference between hard and soft targeting is important as it suggests that it is not the fact that a central bank formally adopts IT that allows a superior performance. Instead, our findings suggest that it is the track record and the ensuing credibility of an IT central bank that allows it as well as the fiscal authority to respond differently and more successfully to the economic shock induced by a natural disaster. 
Our paper relates to a large literature on the impact of IT on macroeconomic outcomes. Most of the literature focuses on the unconditional effects of inflation targeting. In a seminal contribution, Ball and Sheridan (2004) find no significant differences in inflation and growth between IT and non-IT countries in a sample of OECD member states and based on a difference-in-difference approach. Similarly, Lin and Ye (2007) detect no effect of IT on either inflation or inflation variability in industrial countries when employing propensity score matching. Using OLS to study the impact of IT on disinflation periods in OECD countries, Brito (2010) concludes that inflation targeters were not able to bring inflation down at less output costs than non-targeters. On the other hand, Gonçalves and Carvalho (2009) find in a sample of OECD countries that inflation targeters suffer significantly smaller output losses for reducing inflation when using Probit or Heckman regressions. Moreover, Lin and Ye (2009) and Lin (2010) show evidence based on propensity score matching that IT lower inflation and inflation variability in developing countries. Regarding different country samples, De Mendonça and e Souza (2012) find, based on propensity score matching, that IT may be particularly beneficial in developing countries, suggesting that IT might work if it helps improve the credibility of monetary authorities. Overall, this literature seems to conclude that IT matters in particular for developing economies and is less relevant for advanced economies. Our results differ from this literature by focusing on the conditional effects in the aftermath of large shocks. Further, we show in a robustness section that the baseline results hold for both country groups.

There is also no consensus in the literature which studies the performance of IT during the global financial crisis. While Rose (2014) finds that IT did not substantially change how a country weathered the crisis, Carvalho Filho (2010) and Andersen et al. (2015) present evidence that IT countries fared significantly better during this episode. Our findings are in support of the latter view, since IT helps to buffer large disaster shocks better than alternative monetary regimes. We separate from the existing work as our results are obtained conditional on large exogenous shocks, thereby addressing the endogeneity problem related to the episode of the global financial crisis.

To the best of our knowledge, our paper is the first one to analyze whether inflation targeting is effective as a shock absorber in response to large real shocks. Our econometric approach, which has not been used before to study the macroeconomic impact of IT, has several advantages. First and foremost, estimating the conditional effect 
of IT, given an exogenous event, bypasses the need to directly deal with the potentially endogenous choice of the monetary regime to macroeconomic conditions as it "nets out" the unconditional impact of IT on the response variables. The methodological approach is inspired by Ramcharan (2007), who uses disasters to evaluate the effects of exchange rate regimes on the adjustment to real shocks in developing countries.

The remainder of the paper is structured as follows. Section 2 formulates the main hypotheses. It also describes the empirical strategy and the data. Section 3 contains the core results. Section 4 provides extensive sensitivity analysis, before the final section concludes.

\section{Empirical strategy and data}

In this section, we characterize how inflation targeting can affect the policy response to and propagation of large natural disasters. This reasoning is used to derive our empirical hypotheses. We then describe the dataset and the empirical model used to test them.

\subsection{Inflation targeting and the effects of large natural disasters}

In line with the literature, we interpret a natural disaster as an adverse shock to physical capital and durable consumption goods. ${ }^{1}$ The empirical response to such a shock will be affected by two factors: the propagation of the shock within the economy and the policy response to the shock. We suppose that both are affected by the choice of the monetary policy regime.

Inflation targeting (IT) might affect the policy response along two dimensions. First, it imposes constraints on policymakers. Following Svensson (2010), IT can be described as a framework under which the central bank publicly announces an official numerical target or target range for the inflation rate over a specific time horizon. Monetary policy under IT is therefore often described as 'constrained discretion' (Bernanke and Mishkin, 1997; Kim, 2011). IT is associated with enhanced communication standards of monetary authorities with the public and aims at increasing accountability, possibly through implicit incentives or explicit contracts for central bankers. The monetary authority also explicitly communicates that low and stable inflation is its main goal, bases its decisions on inflation forecasts, and enjoys a high degree of independence.

\footnotetext{
1 These shocks share essential features with shocks to the quality of capital or the capital depreciation rate, which have been at the heart of the global financial crisis. One important caveat applies to this generalization. Liu et al. (2011) show in an estimated DSGE model of the US economy that while a shock to the rate of capital depreciation is contracting output it is also disinflationary. In contrast, our natural disaster shock leads to a rise in inflation on impact in the data, as we show below.
} 
These features ideally make announced inflation targets more credible under IT. The main advantage over alternative monetary regimes is thus that IT addresses the dynamic inconsistency problem (Kydland and Prescott, 1977). Clarida et al. (1999) show that stronger commitment allows the central bank to affect agents' inflation expectations directly. Lower and better anchored inflation expectations, in turn, reduce the short-run tradeoff between inflation and output (Walsh, 2009). According to a forward looking Phillips curve, inflation depends on future output gaps. A natural disaster lowers potential output through the destruction of productive capital. This raises inflation. The central bank would like to give the signal that it will be tough in the future without reducing demand much today. This strategy can lower inflation today, while keeping output at potential. However, such a strategy is only credible under commitment, which IT facilitates to attain.

Bernanke and Mishkin (1997) highlight that lower uncertainty about future inflation supports savings and investment decisions and reduces the riskiness of nominal financial and wage contracts. This can impact the propagation of natural disasters for two reasons. First, lower nominal uncertainty in wage contracts might allow for higher employment following disasters. Strulik and Trimborn (2014) show in a macro model that the GDP impact of natural disasters is affected by households' labor response. In their model, a disaster destroys physical capital and durable consumption goods, such as residential housing. Households want to provide more labor in order to rebuild housing, which enters their utility function directly and exhibits a high relative marginal utility. This response in labor supply partially off-sets the negative effect on GDP due to the destruction of physical capital. The off-setting effect is stronger if firms are more willing to demand labor, which is more likely if they face less nominal wage uncertainty. This can dampen the drop in GDP under IT, while simultaneously leading to a rise in durable goods demand and production.

Second, investment activities in a reconstruction-led boom can be positively affected by IT through lower riskiness in nominal credit contracts and higher savings (Benson and Clay, 2004). While this has a dampening effect on the short-run decline in GDP in response to a natural disaster, the literature is inconclusive whether there is a medium to long-term positive growth effect from natural disasters, either through substitution into human capital investment (Skidmore and Toya, 2002) or faster adoption of new technologies (Hallegatte and Dumas (2009). Finally, the response of investment to natural 
disasters also depends on countries' capacities to fund the reconstruction (Kousky, 2014). IT might lower credit constraints through higher savings and lower nominal uncertainty, supporting the recovery.

These considerations lead to the following hypotheses. When a country is hit by a large natural disaster, we expect that inflation targeting, first, dampens the increase in inflation and cushions the drop in output growth, and, second, reduces the variability of both inflation and output growth. In the following we present the data as well as the empirical strategy to test these hypotheses.

\subsection{Data description}

\subsubsection{Large Natural Disaster Shocks.}

We use the EM-DAT database from the Center for Research on the Epidemiology of Disasters (CRED) to select large natural disasters. ${ }^{2}$ The database provides detailed information on disasters such as earthquakes, floods and storms, among others, which occurred worldwide since 1900. The data is compiled from various sources, including UN agencies, non-governmental organizations, insurance companies, research institutes, and press agencies. There are low threshold criteria for events to be registered. One condition out of the following four needs to be met: 10 or more people are killed; 100 or more people are affected; there is a declaration of a state of emergency; there is a call for international assistance. The low thresholds lead to many observations that require filtering for large disasters, as our research question focuses on extreme shocks which have economic consequences on a national scale.

To this end, we follow the existing literature on the macroeconomic consequences of disasters (Noy, 2009). In particular, we use the reported estimated damage, which is the direct damage to property, crops, and livestock, reported in US dollars and valued at the moment of the event. To be as precise as possible, we weight the reported damage according to the occurrence of the event within a quarter, reflecting that a natural disaster taking place at the beginning of the quarter has a larger impact on quarterly output, say, than one towards the end. The weighted reported damage is calculated as $\mathrm{wDAM}=\mathrm{DAM}(3-\mathrm{OM}) / 3$, where $\mathrm{OM}$ denotes the onset month, that is, the reported starting month of the natural disaster. In the sensitivity analysis we show that our results are

\footnotetext{
${ }^{2}$ Guha-Sapir, Below, Hoyois - EM-DAT: International Disaster Database - www.emdat.be - Université Catholique de Louvain, Brussels, Belgium.
} 
robust to alternative weighting schemes. Next, we sum over all weighted damages across events within the same quarter that are classified as natural disasters. ${ }^{3}$ This is motivated by our focus on the economic consequences of extreme shocks in general, abstracting from the specific type of event. We standardize the disaster size by dividing the weighted and aggregated reported damage by the level of nominal GDP one year prior to the event. Thereby, we obtain a continuous variable which can be interpreted as the shock size in percent of GDP.

Figure 1: Distribution of large disaster shocks in targeting and non-inflation targeting countries over time
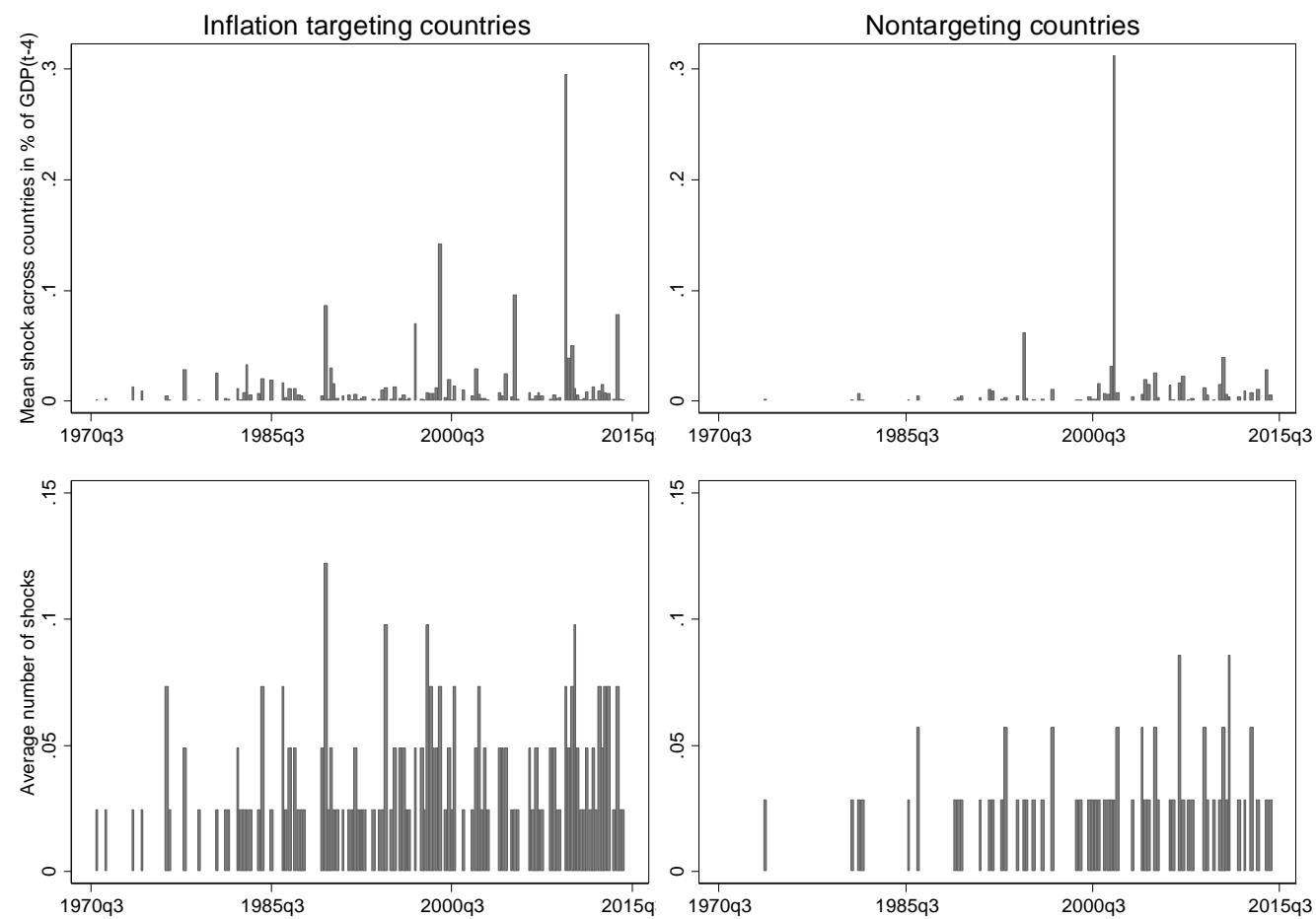

Note: The figure shows the mean shock in inflation targeting and non-inflation targeting countries as percent of GDP(t-4) over time and the average number of large natural disasters in both country groups over time.

The selection of disasters leaves us with 1.953 events over the years 1970 to 2015. We further reduce the number of events in two steps as we are interested in the economic adjustment process to real shocks that are of national economic relevance and since we aim at eliminating noise in the reporting of disasters. First, we take the upper 50th percentile of the our damage variable, that is, the observations with relatively large direct costs. Second, we select from those the episodes which are associated with large drops in

\footnotetext{
3 These fall in either of the following categories: geophysical, meteorological, hydrological, climatological, biological and extraterrestrial. We exclude technological disasters.
} 
GDP growth. We do this by computing the percentiles of contemporaneous GDP growth relative to trend conditional on a large disaster to occur and select the bottom 50th percentile. This procedure gives us 254 events for the subsequent analysis: 79 large disasters under IT and 175 shocks under alternative monetary regimes.

We focus on those disaster episodes that lead to a substantial reduction in GDP growth since we are not interested in the macroeconomic effects of natural disasters per se but in an evaluation of the conditional impact of alternative monetary regimes given a large shock. The reported insurance damage in US dollars is a proxy measure of the direct macroeconomic effects of natural disasters. The selection of large reductions in GDP growth allows us to capture also the indirect effects, such as supply chain disruptions as documented by Inoue and Todo (2017) that might vary across disasters and are not part of reported insurance damages. The selection of large contemporaneous drops in GDP growth is also backed by recent findings in the literature on the growth effects of natural disasters (Noy, 2009; Felbermayr and Gröschl, 2014). Moreover, in the sensitivity analysis we show that our main results hold when using different thresholds in the first step of the shock selection procedure or when leaving out the second step.

\subsubsection{Inflation targeting.}

Regarding the monetary regime, we compile a dataset that distinguishes between inflation targeting and non-inflation targeting regimes. The dates at which a country adopted IT feature some heterogeneity in the literature, depending on the criteria used. While some studies classify a monetary authority to follow IT after simply having announced numerical targets for inflation, others use dates when IT has been effectively implemented. This implementation implies that other nominal anchors like exchange rate targets are abandoned. ${ }^{4}$ We follow Roger (2009) and create a dummy variable for the quarter-country pairs with an effectively implemented IT regime. ${ }^{5}$

We consider the European Central Bank to follow an implicit IT regime and declare countries that have adopted the euro as inflation targeters when they enter the common currency. Member countries which introduced IT before joining the euro are classified as targeters from the initial adoption of IT onwards. In a sensitivity analysis we show that the results are not driven by this classification of euro area countries. Table A1 in the

\footnotetext{
4 The difference between these two dating conventions is referred to in the literature as 'soft IT' versus 'fully fledged IT' (Vega and Winkelried, 2005).

${ }^{5}$ We update this list with countries that have adopted inflation targeting since 2007 by collecting data available from central bank websites.
} 
Online Appendix provides an overview of IT and euro adoption dates. In the sample, we have 41 countries that adopted IT and 35 countries that did not.

Figure 1 brings together the data on natural disasters and inflation targeting. It shows the distribution of the mean size and the average number of large disasters for targeters and non-inflation targeters over time. While the average size and frequency of the shocks tend to be larger for the former, both groups are affected by disasters. Importantly, in the group of countries that adopted IT, there are large and numerous shocks both before and after the spreading of this monetary regime in the 1990s and 2000s. Finally, the figure indicates an overall increase in the number and size of disasters across time. This is a well-known fact in the literature on natural disasters, which we aim to capture through time fixed-effects in the empirical implementation.

\subsubsection{Other macroeconomic data and controls.}

We collect macroeconomic data at a quarterly frequency for the period 1970Q1 to 2015Q4. The cross-section contains 76 countries, mostly advanced economies and emerging markets. The panel dimensions are dictated by the joint availability of the main variables used in the analysis. We start 20 years before the first introduction of IT in New Zealand in 1990Q1 to increase the estimation precision for the control group of countries without IT. The results are insensitive to using only observations from 1990 onwards. One also has to bear in mind that the results, even though the sample contains the global financial crisis, are likely to be influenced by the "great moderation" period.

Table A2 in the Online Appendix lists all countries in the sample. We obtain real and seasonally adjusted data on output, private and government consumption, investment, exports and imports from the OECD national accounts statistics, as well as from national sources. If seasonal adjusted data are not available, we make this transformation by our own. We further obtain CPI price indices, money market rates, and lending rates from the IMF International Financial Statistics. We compute CPI-based real exchange rates relative to the US using bilateral nominal exchange rates and CPI differences as real effective exchange rates are not available at the quarterly frequency for our country sample. The policy rate of the monetary authority and the three month T-Bill rate are from Datastream, while bank lending rates and longer term sovereign yields are from the IMF International Financial Statistics database. 
We clean the data with respect to periods of extraordinary large nominal fluctuations. Specifically, we drop all observations for a given country during periods of extremely high nominal volatility, when either the policy, the inflation or the nominal exchange rate exceeds a given threshold of quarterly rate of change. We set relatively high thresholds with the aim at only eliminating periods of large volatility that are due to hyperinflations and not the result of a large shock from a natural disaster, or the global financial crisis. After dropping these periods, we country-wise also drop observations that are separated along the time dimension from the longest continuous sequence of observations to ensure that the country time-series are uninterrupted. We thereby mostly eliminate periods in the 1980s and 1990s. Only for six countries we drop data spanning the global financial crisis and these episodes are driven by extraordinary country-specific events, like in the Ukraine in response to the Crimea conflict post 2014. Moreover, we have verified that our results are largely insensitive to alternative thresholds. ${ }^{6}$

Finally, we collect a number of control variables. We obtain annual data on total population and the degree of urbanization as a percentage of the total population living in cities from the World Bank. These country characteristics have been used in the literature to control for the possible differential impact of natural disasters across countries. As a proxy for the level of democracy, we use the polity IV variable from the Center for Systemic Peace. Table A3 in the Online Appendix provides an overview of the variables and sources.

\subsection{Empirical model and identification}

In a first specification, we measure the average dynamic effects of the shocks across countries, using the following model:

$$
\Delta y_{i, t}=c+v_{i}+v_{Y}+\sum_{l=1}^{L} \mu_{l} \Delta y_{i, t-l}+\sum_{j=0}^{J} \beta_{j} S_{i, t-j}+\phi X_{i, t-4}+\varepsilon_{i, t} .
$$

$\Delta y_{i, t}$ denotes the quarterly rate of change in the dependent variable for country $i$ in quarter $t$. The main endogenous variables of interest are changes in GDP, consumer prices, and the policy rate. The natural disaster is captured by $S_{i, t-j}$.

To account for time-invariant country characteristics, such as the geographic exposure to large natural disasters, we include country fixed-effects $v_{i}$. Moreover, we allow for year fixed-effects $v_{Y}$ to correct for common unobservable time-varying factors, such as global

\footnotetext{
6 The main results are based on thresholds of 20 percent for the quarterly change of inflation, 40 percent for the nominal exchange rate, and 20 percent for the policy rate. The results hold when changing the thresholds by \pm 10 percentage points.
} 
growth and inflation trends as well as climatic change. To remove possible autocorrelation in the error term, we include lags of the dependent variable. This makes our approach similar to the single-equation regressions of Romer and Romer (2004) and Kilian (2008) for the analysis of monetary policy and oil supply shocks, respectively. In the sensitivity analysis, we use alternative estimators to confirm that our results do not suffer from the Nickell bias (Nickell, 1981), as can be expected in our sample where the time-dimension is long ( $\mathrm{T}>30$, see Judson and Owen, 1999). Finally, we add several timevarying control variables in the vector $X_{i, t-4}$. They include the degree of urbanization, population density and a measure for the level of democracy and enter at a lag of four quarters in order to prevent endogenous feedback with disaster shocks. We set $J=15$ and $L=4$ to obtain impulse responses over a horizon of four years and to ensure that the residuals are free of autocorrelation. We estimate (1) by OLS based on a withintransformation, assuming that the error term $\varepsilon_{i, t}$ is independent and identically distributed.

In a second specification, we extend (1) by including an IT-dummy, $I T_{i, t-j}$, in levels and as an interaction with the shock to estimate the differential effect of inflation targeting in the aftermath of large natural disaster shocks:

$$
\Delta y_{i, t}=c+v_{i}+v_{Y}+\sum_{l=1}^{L} \mu_{l} \Delta y_{i, t-l}+\sum_{j=0}^{J}\left[\beta_{j} S_{i, t-j}+\gamma_{j} I T_{i, t-j} S_{i, t-j}+\delta_{j} I T_{i, t-j}\right]+\phi X_{i, t-4}+\varepsilon_{i, t}
$$

The main parameters of interest are now the $\gamma_{j}{ }^{\prime} s$. They capture the difference between the dynamic effects of large real shocks under inflation targeting and non-inflation targeting regimes. The specification thereby also relaxes the standard assumption in panel data models of common slopes across all panel units. Throughout, we base statistical inference on 500 Monte Carlo draws. ${ }^{7}$

To illustrate the identification strategy, we consider the case of $J=L=0$ and summarize all explanatory variables in (2) outside the brackets in the vector $Z_{i, t}$. Further, we define as $\mathrm{E}\left(\Delta y_{i, t} \mid S_{i, t}>0, Z_{i, t}\right)$ the expected value of $\Delta y_{i, t}$ given that a natural disaster occurred and conditioned on the set of co-variates $Z_{i, t}$. Following Ramcharan (2007), the average effect of the disaster is then

\footnotetext{
7 Following Romer and Romer (2004), we use the estimated covariance matrix of the coefficients to draw new coefficients from a multivariate normal distribution, from which we compute a distribution of impulse responses.
} 


$$
\begin{aligned}
\mathrm{E}\left(\Delta y_{i, t} \mid S_{i, t}>0, Z_{i, t}\right)-\mathrm{E}\left(\Delta y_{i, t} \mid S_{i, t}\right. & \left.=0, Z_{i, t}\right)=\beta_{0} S_{i, t}+\gamma_{0} \mathrm{E}\left(I T_{i, t} \mid S_{i, t}>0, Z_{i, t}\right) S_{i, t} \\
& +\delta_{0}\left[\mathrm{E}\left(I T_{i, t} \mid S_{i, t}>0, Z_{i, t}\right)-\mathrm{E}\left(I T_{i, t} \mid S_{i, t}=0, Z_{i, t}\right)\right] \\
& +\left[\mathrm{E}\left(\varepsilon_{i, t} \mid S_{i, t}>0, Z_{i, t}\right)-\mathrm{E}\left(\varepsilon_{i, t} \mid S_{i, t}=0, Z_{i, t}\right)\right] .
\end{aligned}
$$

We make two assumptions to simplify (3). First, the residual $\varepsilon_{i, t}$, which captures unobserved drivers of $\Delta y_{i, t}$, is unrelated to the occurrence of the disaster shock $S_{i, t}$. The assumption is motivated by the random nature of these shocks and our strategy of accounting for country characteristics that capture the general susceptibility to these shocks. Then, $\mathrm{E}\left(\varepsilon_{i, t} \mid S_{i, t}>0, Z_{i, t}\right)=\mathrm{E}\left(\varepsilon_{i, t} \mid S_{i, t}=0, Z_{i, t}\right)=0$.

Second, natural disaster shocks do not systematically affect the choice of the monetary regime. This assumption is motivated, on the one hand, by the remarkable stability of inflation targeting as a monetary regime (Rose, 2007; 2014). No country that adopted IT has ever abandoned it. This stability rules out the possibility that a country abolished IT in response to a large natural disaster. On the other hand, it is easy to check whether in our sample countries adopted IT (in the four years) following a large shock. We find only three such cases and excluding them from the analysis does not change the results. We can thus essentially exclude the possibility that the decision to target inflation depends on disaster realizations. Nevertheless, we test this assumption formally by estimating a set of probit models where the dependent variable is the probability that a country targets inflation. We include several institutional and economic country characteristics as explanatory variables, following Lin and Ye (2007), Gonçalves and Carvalho (2009), and Lin (2010), in addition to geographic factors measuring the exposure of countries to natural disasters. Moreover, we add our shock variable with lag 0-15 to test whether it affects the probability of targeting. Table A4 in the Online Appendix shows that none of the shock lags is individually significant, and that they are jointly insignificant as well. The p-values of the corresponding F-tests are all close to one. All in all, we hence assume that $\mathrm{E}\left(I T_{i, t} \mid S_{i, t}>0, Z_{i, t}\right)=\mathrm{E}\left(I T_{i, t} \mid S_{i, t}=0, Z_{i, t}\right)=I T_{i, t}$. Under these two assumptions (3) simplifies to

$$
\mathrm{E}\left(\Delta y_{i, t} \mid S_{i, t}>0, Z_{i, t}\right)-\mathrm{E}\left(\Delta y_{i, t} \mid S_{i, t}=0, Z_{i, t}\right)=\beta_{0} S_{i, t}+\gamma_{0} I T_{i, t} S_{i, t},
$$

where $\gamma_{0}$ measures the difference between the average effect of the shock under targeting and non-inflation targeting regimes. However, to attach a causal interpretation to $\gamma_{0}$, we need to carefully control for other potential country features that could affect both the choice of the monetary regime and the response of the economy to the shock. In the 
sensitivity analysis, we will therefore extensively control for other potential shock absorbers. In particular, we correct for the level of development and the quality of institutions, as there is evidence that IT is mostly matters for developing countries (Lin and Ye, 2007; Ball, 2010; Lin, 2010), for the exchange rate regime (Ramcharan, 2007), as well as for fiscal policies (Combes et al., 2017) and financial capacities. ${ }^{8}$

\section{Inflation targeting and macroeconomic performance}

In this section, we first present the estimated average effects of large disasters on the macro-economy. Then we test whether IT economies respond differently than noninflation targeting economies. Finally, we highlight several channels through which IT may change the responses.

\subsection{The dynamic effects of large natural disasters}

Figure 2 summarizes the point estimates of the dynamic effects of large disasters on key macroeconomic variables on average across monetary regimes as derived from the $\beta_{j}$ coefficients in equation (1) alongside their 68 and 90 percent confidence bands. We find a significantly negative effect on GDP growth, which declines by about 0.3 percentage points upon impact. It then overshoots for roughly two quarters, before returning to the level where it would have been without the shock. ${ }^{9}$

The economic consequences of natural disasters can be viewed as those of a negative shock to the capital stock of an economy which distorts production. Disasters typically cause direct damages to houses and contents, machinery, and infrastructure as well as indirect impacts due to business interruption. Post-disaster, the replacement of destroyed capital through more productive investments and new technologies, spending of insurance payouts, and possible multiplier effects of increased household and business outlays generate catch-up demand and increase GDP growth.

As production is interrupted, various products - and labor - are in short supply, and more expensive substitutes are used, inflation increases significantly; by about 0.2 percentage points upon impact. When demand surges in the following quarters, inflation

\footnotetext{
8 An alternative identification strategy that eliminates the second step in the shock selection procedure (see Section 2.2.1) would be to use the natural disasters as an instrument for GDP growth and then assess the differential effects of IT given an exogenous change in GDP growth. This approach is not ideal for our research question, however, as we are interested in the response of GDP growth (and volatility) itself under IT.

9 Our analysis does not aim at contributing specifically to the literature on the growth effects of natural disasters, which has not come to a consensus. Cavallo et al. (2013) find no significant effect of large natural disasters on GDP growth once controlling for political turmoil occurring in the aftermath of natural disasters. Loayza et al. (2012) find negative growth effects only for a subset of natural disasters, like earthquakes, windstorms, and droughts, while floods tend to have a mildly positive impact. Kousky (2014) provides a survey of this literature.
} 
rises further to roughly 0.4 percentage points above trend, before the effects fade out. Despite the immediate price pressure, central banks on average aim at countering the drop in output growth by lowering policy rates. When GDP growth recovers and inflation rises further, there is a tendency to tighten policy.

Figure 2: Dynamic effects of large natural disasters on the first (log) differences of key variables
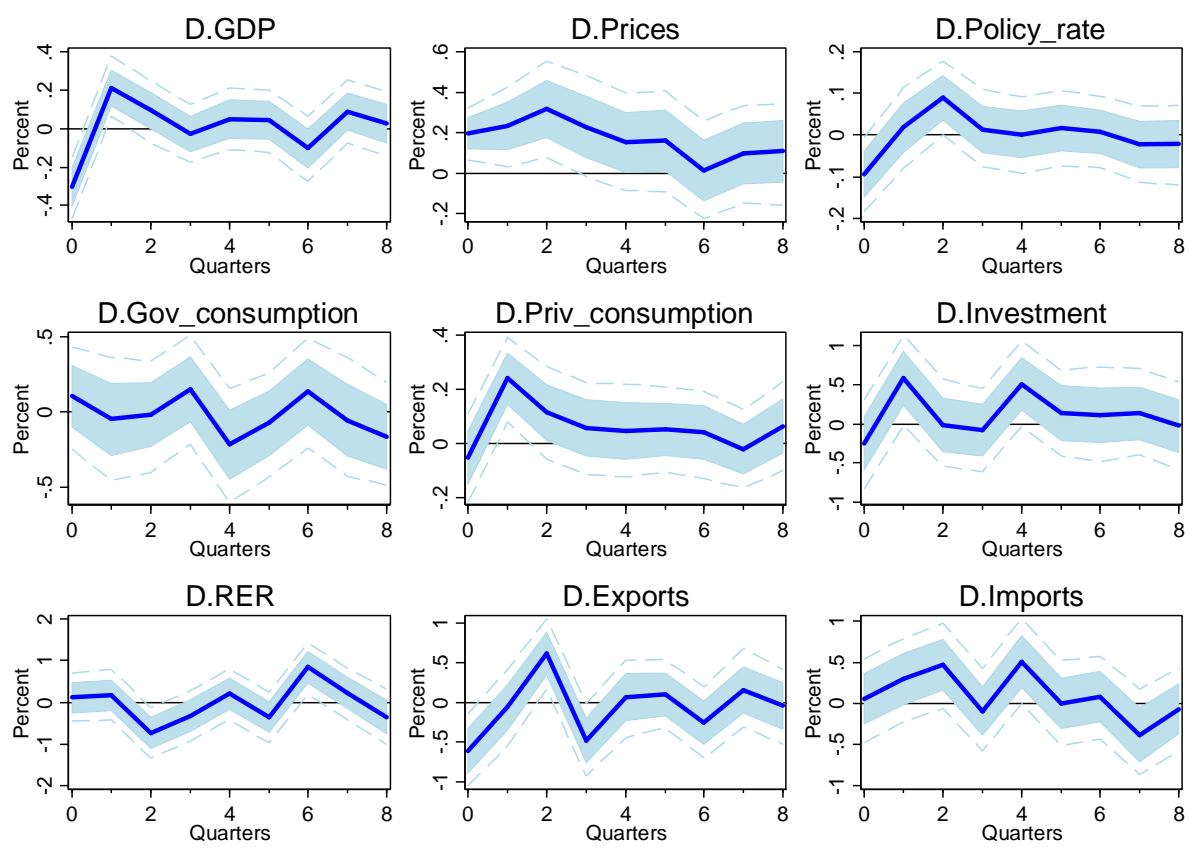

Note: The figure shows the average response of the first $(\log )$ differences of key macroeconomic variables to large natural disasters in a sample of 76 inflation targeting and non-inflation targeting countries over the period 1970Q1-2015Q4. Confidence bands refer to the 68 and 90 percent level and are based on 500 Monte-Carlo draws.

Looking at the components of domestic absorption, government consumption seems largely unresponsive, leaving private consumption and investment as the main drivers of the overshooting of output growth. They both rise significantly in the quarter following the shock. Regarding the external sector, the real exchange rate is not affected much upon impact, as higher inflation and a weaker currency balance each other out, on average with a depreciation contributing to an increase in inflation via higher import prices - but it then significantly appreciates when inflation reaches its peak and policy rates are raised. ${ }^{10}$ Real export growth drops immediately after the shock, contributing to the initial decline in GDP growth, before recovering. Import growth, on the other hand, tends to be above trend simultaneously with the other domestic demand components, and in line

10 A decline in the exchange rate implies an appreciation of the currency. 
with the appreciated real exchange rate. Overall, these findings on the macroeconomic effects of natural disasters are in line with the literature.

Figure 3: Dynamic effects of large natural disasters on the level of key macroeconomic variables
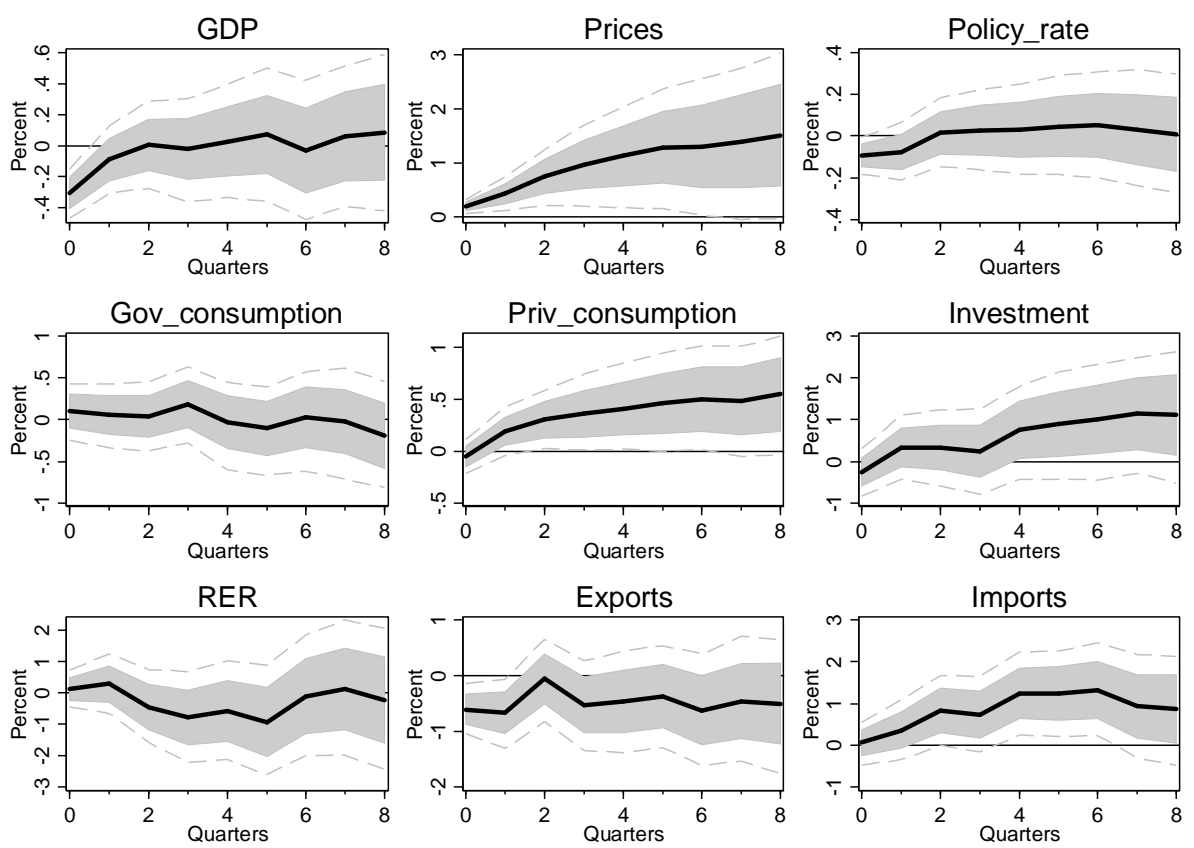

Note: The figure shows the average response of the level of key macroeconomic variables to large natural disasters in a sample of 76 inflation targeting and non-inflation targeting countries over the period 1970Q1-2015Q4. Confidence bands refer to the 68 and 90 percent level and are based on 500 Monte-Carlo draws.

Figure 3 shows the dynamic effects of large natural disasters in cumulative terms. The shocks have long-lasting and significant effects on GDP, several of its components, and consumer prices. After the negative initial impact, the economies start recovering and GDP return to its pre-crisis level after one year. Net exports are a drag on GDP as exports persistently decline and imports increase, consistent with the propensity of the currency to appreciate in real terms. The appreciation, in turn, appears to be a result of the sustained increase in the domestic price level. Finally, monetary and fiscal policy appear largely neutral. The average effects, however, mask important differences in the conduct of both monetary and fiscal policy across monetary regimes, as we will show next. These differences have significant implications also for the evolution of the other variables in each regime.

\subsection{The effects of inflation targeting on macroeconomic dynamics}

We now assess whether and how inflation targeting changes the dynamic adjustment to large real shocks by computing impulse responses for targeting and non-targeting 
economies. We then test whether the responses are significantly different across regimes. For short, we refer to countries operating under IT as targeters and to economies with non-IT regimes as non-targeters, although technically we are using only the within variation in the data given that our model contains country fixed-effects. We concentrate on the level effects, which provide a clearer picture.

Figure 4: Level effects of large real shocks in targeting and non-inflation targeting economies
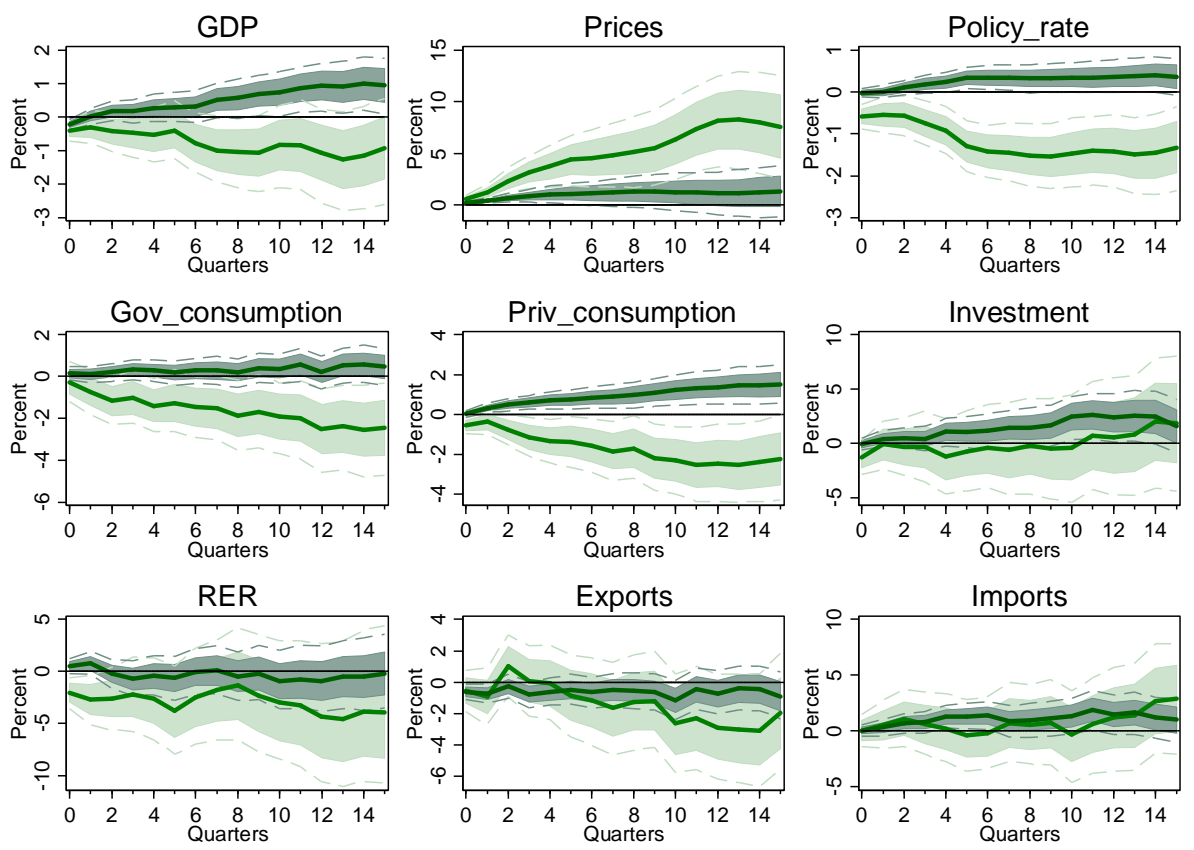

Note: The figure shows the cumulated response of key macroeconomic variables in targeting (dark shaded area) and non-inflation targeting countries (light shaded area) to large natural disasters over the period 1970Q1-2015Q4. Confidence bands refer to the 68 and 90 percent level and are based on 500 Monte-Carlo draws.

Figure 4 shows the adjustment of both groups to the shock, as derived from the estimated coefficients $\beta_{j}, \gamma_{j}$ and $\delta_{j}$ from equation (2). There are a number of significant differences. First and foremost, output is significantly higher and prices increase significantly less under IT. In fact, output persistently rises above the level prevailing in absence of the shock for targeters, whereas it falls below the pre-shock level for nontargeters. Consumer prices tend to rise under both regimes, but only mildly and mostly indistinguishable from zero under IT, while there is a strong and long-lasting price increase otherwise. Together, these findings provide preliminary support for our first hypothesis.

Several mechanisms are relevant for understanding the pronounced differences. Regarding policy, targeters tend to rely on fiscal policy to buffer the adverse shock, 
whereas non-targeters strongly use monetary policy for that purpose. In the latter group central banks aggressively lower policy rates, by cumulatively two percentage points two years after the shock. In sharp contrast, monetary authorities raise interest rates under IT; albeit only mildly and with some lag in response to the pickup in prices. For fiscal policy this pattern is reversed. While targeters accommodate the shock, non-inflation targeters reduce fiscal spending.

We interpret these findings in the light of a coordinating role of IT for monetary and fiscal policy. While it is undisputed that IT requires the absence of fiscal dominance (Sargent and Wallace 1981, Freedman and Ötker-Robe 2010), Minea and Tapsoba (2014) document that the adoption of IT improves fiscal discipline. Thus, a higher coefficient on inflation in the loss function of central banks enforces a sound fiscal position which, in turn, prevents from pro-cyclical public spending in the wake of large disasters.

Next to public, private spending seems to explain a relevant share of the difference in the output responses between regimes. Finally, regarding the external sector, there is some evidence that targeters benefit from a more stable real exchange rate, which tends to appreciate in the other group where consumer prices increase sharply.

Figure 5: Differential level effects of large real shocks between targeting and non-inflation targeting economies
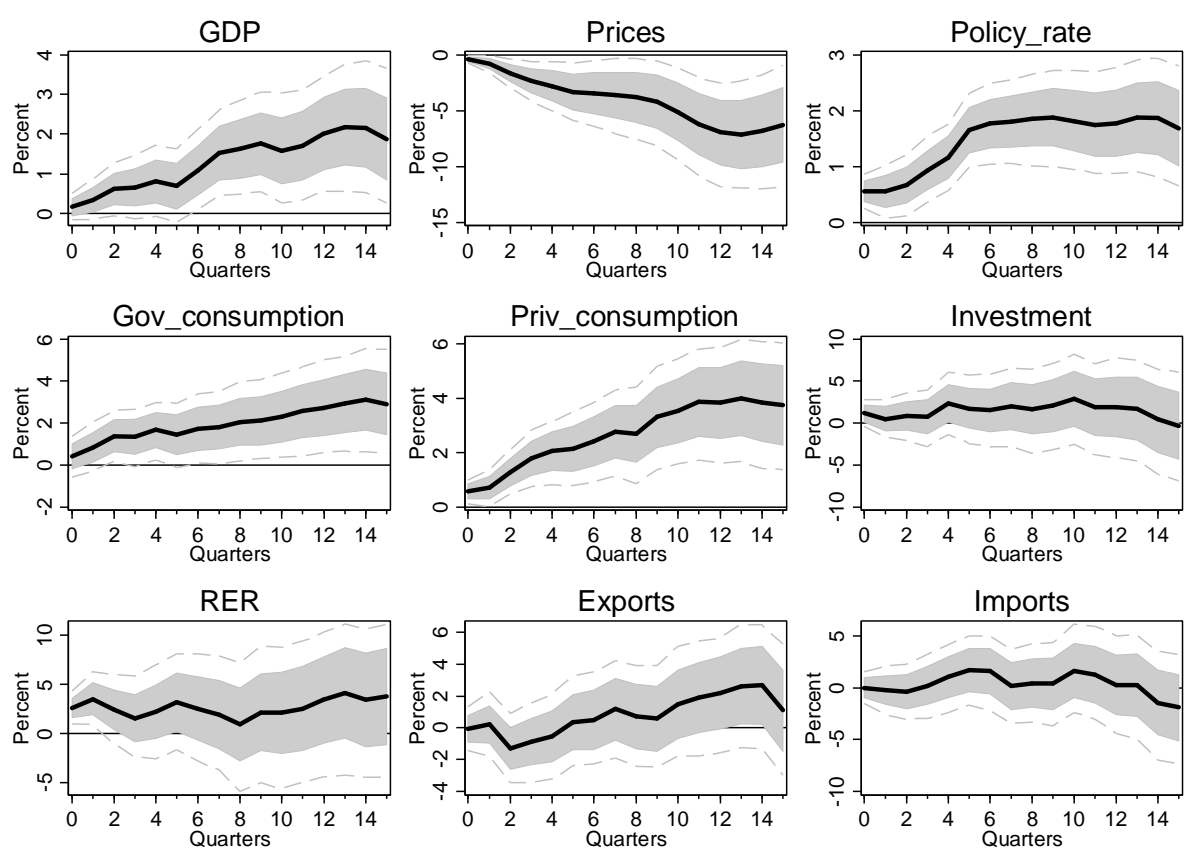

Note: The figure shows the cumulated differential responses between inflation targeting and non-inflation targeting countries of key macroeconomic variables to large natural disasters over the period 1970Q1-2015Q4. Confidence bands refer to the 68 and 90 percent level and are based on 500 Monte-Carlo draws. 
The cumulative differential effects between targeters and non-inflation targeters, that is, the cumulated $\gamma_{j}{ }^{\prime} s$ of model (2), are presented in Figure 5. They add to the evidence in favor of the first hypothesis as they underline the superior performance of targeters. Under IT GDP is significantly higher in the quarter of impact and subsequently. After four years, the difference is roughly 2 percentage points. At the same time, the increase in consumer prices is more than 5 percentage points lower than in non-targeting economies. As indicated earlier, some of these strong differences in the economic effects between regimes seem to be attributable to the direct effects of alternative monetary and fiscal policies across regimes, as well as to the differing paths of private consumption. After four years, the level responses of the respective variables differ by 2,2 , and 4 percentage points, respectively.

To formally evaluate our first hypothesis we compute the average inflation and output growth rate for targeting and non-inflation targeting economies over the response horizon of four years and test whether the means are different across country groups. As the underlying responses are random vectors with distributions, we first investigate the precision and distribution of our estimates of average inflation and output growth, following Cecchetti and Rich (2001). Figure A1 in the Online Appendix plots the empirical density functions of the estimates obtained from the Monte Carlo simulations. ${ }^{11}$ Based on the properties of the empirical densities, we proceed by estimating the means of these distributions and testing whether they are significantly different across regimes.

Table 1 contains the results for output growth and inflation, as well as for the other variables shown in the impulse responses. The first two columns lend further support to the first hypothesis. The average quarterly rate of output growth following a shock is 0.16 percentage points higher under IT, and the average quarterly change in the price level is 0.44 percentage points lower. These differences are statistically highly significant according to the corresponding t-statistics and p-values. The results for the other variables are mostly equally stark and confirm the two reasons for the superior growth and inflation performance of targeters indicated by the impulse response analysis: a different policy mix and better shock absorption through the external sector. All in all, we

\footnotetext{
11 Several observations are worth mentioning. First, the figure corroborates the conclusion based on the impulse response analysis of a significantly better macroeconomic performance of targeting economies, namely higher output growth and lower inflation. For both variables, the distributions overlap only marginally. Second, it shows that the effects for non-targeters are less precisely estimated as the distributions are less concentrated. Third, it indicates that it is reasonable to assume that the true means, which are nonlinear functions of normally distributed variables, are also normally distributed.
} 
conclude that IT significantly reduces inflation and increases output growth when an economy is subject to a large real exogenous shock.

Table 1. Testing for differences in means

\begin{tabular}{|c|c|c|c|c|c|c|c|c|c|}
\hline Variable & $\begin{array}{c}\text { D. } \\
\text { GDP }\end{array}$ & $\begin{array}{c}\text { D. } \\
\text { Prices } \\
\end{array}$ & $\begin{array}{c}\text { D. } \\
\text { Pol. rate } \\
\end{array}$ & $\begin{array}{c}\text { D. } \\
\text { Gov. cons. }\end{array}$ & $\begin{array}{c}\text { D. } \\
\text { Priv. cons. }\end{array}$ & $\begin{array}{c}\text { D. } \\
\text { Investm. }\end{array}$ & $\begin{array}{c}\text { D. } \\
\text { RER }\end{array}$ & $\begin{array}{c}\text { D. } \\
\text { Exports }\end{array}$ & $\begin{array}{c}\text { D. } \\
\text { Imports }\end{array}$ \\
\hline IT & 0.07 & 0.05 & 0.03 & 0.04 & 0.09 & 0.19 & -0.04 & -0.01 & 0.09 \\
\hline non-IT & -0.09 & 0.48 & -0.09 & -0.16 & -0.17 & 0.12 & -0.22 & -0.21 & 0.15 \\
\hline Difference & 0.16 & -0.44 & 0.12 & 0.2 & 0.26 & 0.07 & 0.18 & 0.2 & -0.07 \\
\hline & 51.62 & -40.9 & 68.98 & 44.38 & 59.31 & 6.15 & 12.73 & 26.76 & -7.01 \\
\hline p-value & 0.00 & 0.00 & 0.00 & 0.00 & 0.00 & 0.00 & 0.00 & 0.00 & 0.00 \\
\hline
\end{tabular}

Notes: The table shows the estimated mean of the (log) change of main macroeconomic variables over four years following natural disasters in inflation targeting and non-inflation targeting economies, as well as the differences between the means together with their tstatistics and p-values based on 500 Monte Carlo draws.

\subsection{Macroeconomic volatility and financial frictions}

The finding that IT generates both higher output growth and lower inflation is remarkable given that there is also a contention in the literature whether IT can only reduce inflation at the expense of depressing output (Cecchetti and Rich, 2001; Friedman, 2004; Gonçalves and Carvalho, 2009). Beyond that, the direct effects of the different policy mix adopted by targeting economies seem not to reveal the full story behind the success. There are additional features of IT, however, that are prominently discussed in the literature and which are thought to contribute to its superiority over alternative monetary regimes (Bernanke and Mishkin, 1997): (i) the attainment of a generally more stable economic environment, and (ii) a reduction of financial frictions. In this section, we show empirical evidence in the form of conditional effects of inflation targeting in support of these two aspects of the monetary policy regime.

To test the first argument, we assess the effect of IT on macroeconomic volatility. For this, we again rely on the distributions of the estimated impulse responses and compute, analogously to the procedure for mean growth rates, for each variable the distribution of the standard deviation of its growth rate over the response horizon of four years. With these distributions and the implied average standard deviations at hand, we can formally evaluate our second hypothesis by testing whether IT reduces the variability of inflation and output growth in the aftermath of large real shocks. 
Table 2. Testing for differences in volatility

\begin{tabular}{|c|c|c|c|c|c|c|c|c|c|}
\hline Variable & $\begin{array}{c}\text { D. } \\
\text { GDP }\end{array}$ & $\begin{array}{c}\text { D. } \\
\text { Prices }\end{array}$ & $\begin{array}{c}\text { D. } \\
\text { Pol. rate }\end{array}$ & $\begin{array}{c}\text { D. } \\
\text { Gov. cons. }\end{array}$ & $\begin{array}{c}\text { D. } \\
\text { Priv. cons. }\end{array}$ & $\begin{array}{c}\text { D. } \\
\text { Investm. }\end{array}$ & $\begin{array}{c}\text { D. } \\
\text { RER }\end{array}$ & $\begin{array}{c}\text { D. } \\
\text { Exports }\end{array}$ & $\begin{array}{c}\text { D. } \\
\text { Imports }\end{array}$ \\
\hline IT & 0.16 & 0.15 & 0.07 & 0.29 & 0.13 & 0.46 & 0.64 & 0.48 & 0.44 \\
\hline & 0.28 & 0.45 & 0.23 & 0.66 & 0.36 & 1.16 & 1.14 & 1.09 & 1.05 \\
\hline Difference & -0.12 & -0.30 & -0.16 & -0.37 & -0.23 & -0.70 & -0.50 & -0.61 & -0.61 \\
\hline t-statistic & -46.99 & -64.52 & -92.04 & -53.66 & -79.55 & -66.95 & -50.16 & -69.29 & -66.17 \\
\hline p-value & 0.00 & 0.00 & 0.00 & 0.00 & 0.00 & 0.00 & 0.00 & 0.00 & 0.00 \\
\hline
\end{tabular}

Notes: The table shows the estimated average standard deviation of the (log) change of main macroeconomic variables over four years following a large real shock in inflation targeting and non-inflation targeting economies, as well as the differences between the mean standard deviations together with their t-statistics and p-values based on 500 Monte Carlo draws.

Table 2 presents evidence in favor of argument (i). All standard deviations are significantly lower under IT. This observation holds for both nominal and real variables as well as for the domestic and external sector. The differences are all highly statistically significant. ${ }^{12}$ Regarding the domestic economy, the standard deviation of inflation is roughly 30 percentage points lower under IT, and that of output growth is about 10 percentage points smaller. Based on these results, we accept the second hypothesis. Regarding the external economy, lower volatility of real exchange rate growth is coupled with lower fluctuations in export and import growth. Together with the model-consistent superior output growth performance under IT documented in the previous section, these differences in volatility lend empirical support to the idea that IT supports output growth by establishing a generally more stable macroeconomic environment. This stability could also influence the degree of financial frictions in an economy.

We focus on two particular types of frictions to evaluate argument (ii): credit risk premia and term premia. To see whether the behavior of these premia is affected by the monetary regime, we study the dynamic behavior of different private and public interest rates. The first panel of Figure 6 repeats the differential response of the policy rate between targeting and non-inflation targeting regimes for comparison. The following panels contain the differences in the behavior of the short-term Treasury bill rate, the money market rate, and the lending rate of the private sector.

The panels show that there are substantial differences in the pass-through of monetary interventions from the public to the private sector across regimes. While the difference between the responses of the policy and the T-Bill rate is roughly 2 percentage points on

\footnotetext{
12 The empirical density functions for the estimated standard deviations are shown in Figure A2 in the Online Appendix. As with the density functions for estimated means, they all appear to be well, that is, normally shaped.
} 
average over four years, this gap narrows to 1.5 percentage points for the money market rate and to 1 percentage point for the lending rate. In the latter case, the difference is also less statistically significant. These numbers and underlying interest rate dynamics suggest that larger countercyclical private credit risk premia reduce the effectiveness of monetary policy under non-inflation targeting regimes, partially explaining their poorer output performance notwithstanding aggressive monetary easing.

Figure 6: Differential response of monetary policy and interest rates to large natural disasters between targeting and non-inflation targeting economies
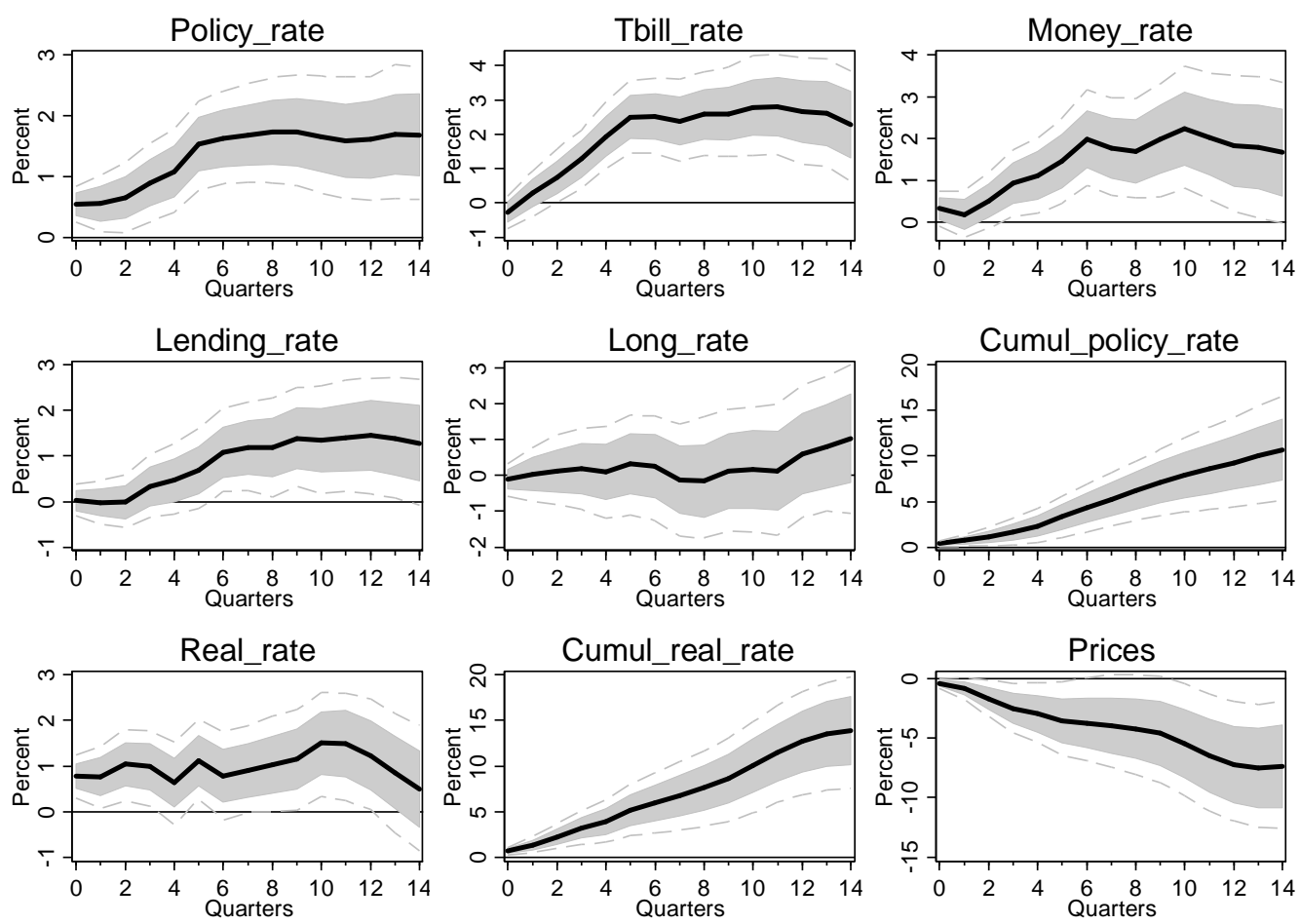

Note: The figure shows the difference between the responses of public and private interest rates in inflation targeting and non-inflation targeting economies to large natural disasters over the period 1970Q1-2015Q4. Statistical inference is based on 500 Monte-Carlo draws.

What is striking, is that despite the sharp relative increase of the T-Bill rate in targeting economies, there is no significant difference in the path of long-term rates (see middle panel). Taken together, this suggests that the term premium responds quite differently across monetary regimes. The expectations hypothesis of the term structure in its linear form implies that the nominal long-term rate is the sum of the path of the current and future expected nominal short-term rates and the term premium. To obtain a measure of the expected short rates, we compute and plot the cumulative difference in the policy rate. The sharp increase of this variable can only be consistent with an essentially 
unchanged difference in the long rate if the difference between the term premia in targeting and non-inflation targeting economies strongly declines. Indeed, the groupspecific responses suggest that the term premium remains roughly constant under IT, whereas it sharply increases otherwise, such that the differential term premium drops (see Figure A3 in the Online Appendix).

We reach similar conclusions when looking at the behavior of expected real rates and inflation. The standard term structure theory further implies that the nominal long rate is the sum of current and future expected real short rates, expected inflation, and the term premium. To obtain a measure of expected real short rates we first estimate the response of current real rates, computed as the difference between the policy rate and realized inflation, and then cumulate the response. To approximate expected inflation, we employ the model-based change in the price level. As the figure shows, the relative increase in the expected real rates for targeters is quantitatively not fully compensated by relative declines in inflation expectations, which implies that the relative term premium must decline for the difference in the nominal long rate to remain stable. Altogether, the results of the subsection help to understand why a strong monetary stimulus coupled with a mild fiscal contraction in non-inflation targeting economies yields significantly inferior outcomes than a moderate monetary tightening with fiscal accommodation under IT.

\section{Sensitivity analysis}

In this section we perform various sensitivity tests to see whether our main results are robust. We conduct sample splits and we control for other potential shock absorbers. In the Online Appendix, we run a large number of further tests: we consider modified versions of the shock and IT measures, use an alternative estimator as well as different model specifications, and estimate models with triple-interaction terms between the shock, the IT dummy, and a third variable.

\subsection{Subsample estimates}

We split the sample into developed and developing countries to find out whether one of the groups is driving the results. The reason for this division is that, on the one hand, richer economies might be more likely to adopt IT, given their more developed democratic and financial institutions, and at the same time are better prepared to weather large disasters. On the other hand, there is evidence that the introduction of IT has a stronger impact on economic performance in developing economies (Ball, 2010; De 
Mendonça and e Souza, 2012). Lin and Ye (2007), for example, find no effect of IT in seven industrial countries, whereas Lin (2010) detects a significant impact of IT in developing countries.

Figure 7: Differential responses between targeting and non-inflation targeting economies in subsamples
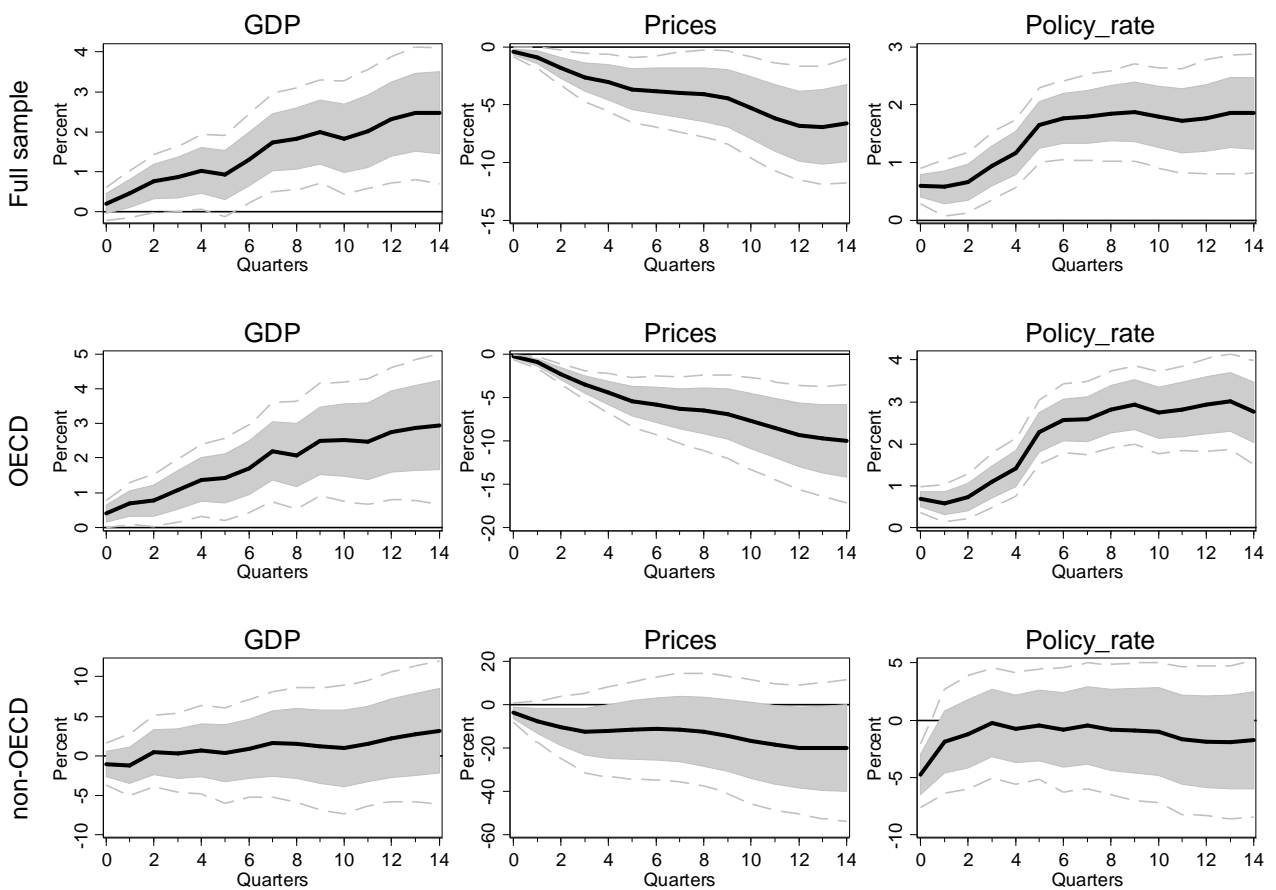

Note: The figure shows for alternative subsamples the differential response of the level (cumulated first (log) difference) of GDP, prices and the policy rate across targeting and non-inflation targeting countries to large natural disasters over the period 1970Q1-2015Q4. Row (1) shows the baseline results using the full sample for comparison. In row (2), the sample is restricted to OECD member countries. In row (3), the sample is restricted to non-OECD member countries. Confidence bands refer to the 68 and 90 percent level and are based on 500 Monte-Carlo draws.

We re-estimate model (2) for two subsamples. First, we look at countries that are members of the OECD. Second, we look at the complement subsample of countries which are not OECD members. Figure 7 shows the differential level responses under IT and nonIT regimes in the subsample. The baseline results for the full sample are in the first row for comparability. The dynamic responses of the OECD subsample are qualitatively and quantitatively similar to the baseline results. GDP is higher, prices increase less, and monetary policy is more restrictive. This picture changes somewhat for the subsample of non-OECD countries. The difference in output performance largely vanishes, but prices remain lower in IT countries despite the initial relative easing of monetary policy. We conclude that both developed and developing economies benefit from an improved macroeconomic performance under IT, but the baseline results seem to be mainly driven by the OECD sample. 


\subsection{Does hard or soft targeting make a difference?}

As a next step we try to determine whether the adoption of IT per se generates macroeconomic improvements. Such a finding would speak against the "conservative window-dressing" view which postulates that the very features of IT have little effects on output or inflation and instead the stronger emphasis of the central bank on inflation and the corresponding conduct of monetary policy achieves the better outcomes (Romer, 2006).

Figure 8: Duration of missed inflation targets

A. Average duration of spells of missed target

B. Max. duration of missed target
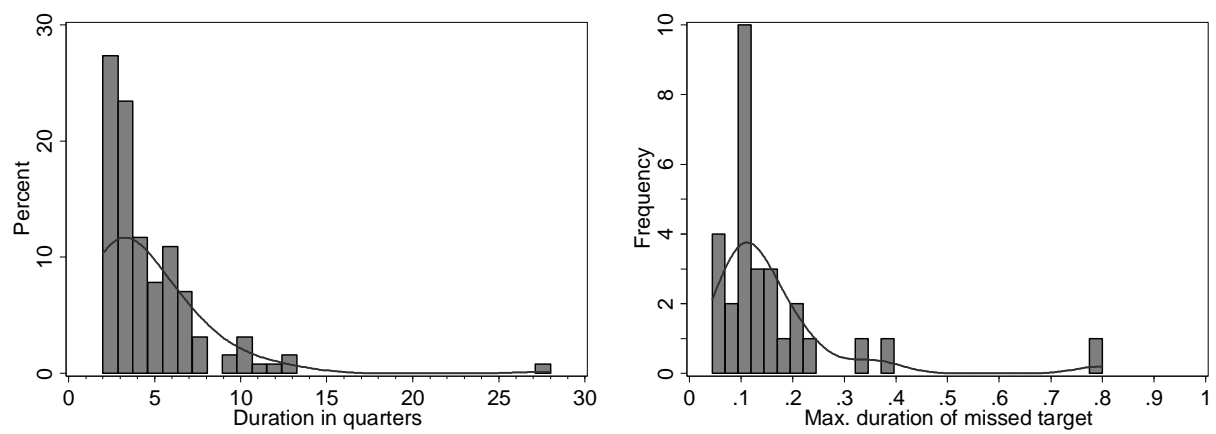

Note: Panel (A): Density of average duration spells where the inflation rate is outside the target corridor in the sample of countries operating under an inflation targeting regime. "Target misses" are defined as observed CPI inflation rates outside of the target corridor. The solid line represents the kernel density estimate of a Gaussian kernel function with a bandwidth of 2 and 0.05 , respectively. PANEL (B): Density plot of the longest time period of a one-sided, continued realized inflation rates outside of the corridor per country in the sample operating under IT. The maximum duration of a missed inflation target is expressed in percent of the total number of quarters under IT.

To test this argument we split the IT group into a hard targeting group that ex post complies more strictly with the inflation target versus a soft targeting group that ex post complies less with the inflation target. We measure compliance as the maximum time spell of consecutive recordings of inflation rates outside of the target corridor. ${ }^{13}$ Figure $8 \mathrm{a}$ shows the histogram of the average duration of target misses in the sample. There is no country with an average duration of target misses at zero or one quarter and the highest density is at two quarters, rapidly declining to 14 quarters. There are outliers of up to 27 quarters of continued misses. Figure $8 \mathrm{~b}$ exhibits the maximum one-sided duration spell of each IT country. It is expressed in percent over the total number of quarters under IT. This is the measure that we use to separate hard from soft inflation targeters. We split the

\footnotetext{
13 We compiled a database for the inflation targeting countries and their respective target rates and target corridors. Where no corridors are used for the conduct of IT, we constructed a symmetric and hypothetical corridor around the target rate with the average size of target corridors across countries. Figure A4 and Figure A5Error! Reference source not found. in the Online Appendix illustrate this for the entire sample of IT countries.
} 
sample according to the $50^{\text {th }}$ percentile of the maximum duration spell of target misses. This leads to a threshold value of 11.4 percent. Thus, the countries with a maximal onesided deviation from target of more than 11.4 percent of the total number of quarters under IT are declared as soft IT counties.

Figure 9: Does hard or soft inflation targeting improve performance?
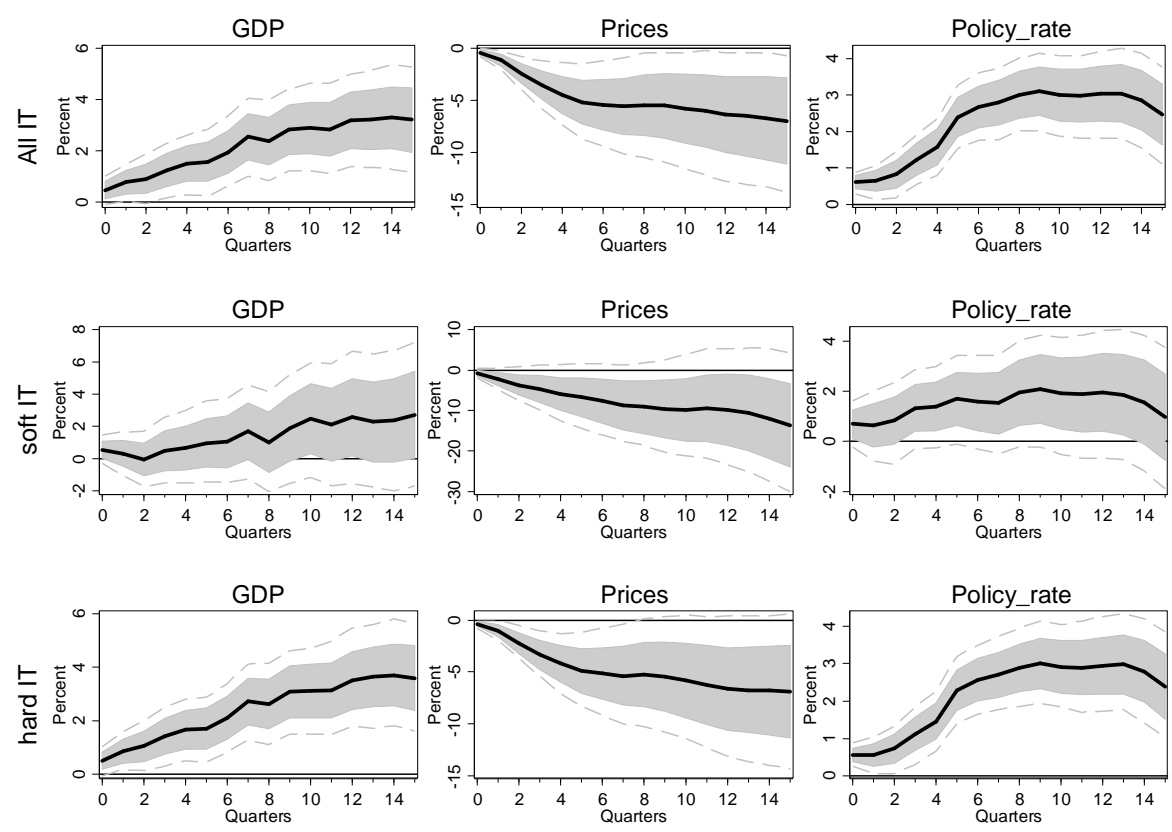

Note: The figure shows the difference between the responses of the level (cumulated first (log) difference) of all inflation targeting, only less-complying IT countries, and only complying IT countries, respectively, versus all non-inflation targeting economies to large natural disasters over the period 1970Q1-2015Q4. Confidence bands refer to the 68 and 90 percent level and are based on 500 MonteCarlo draws.

Our classification follows the idea that temporary deviations from the inflation target are fully in line with an inflation target which should be reached over the medium term, while different shocks drive the actual inflation rate occasionally out of the target range. In fact, there is no country in our sample for which inflation has never deviated from the target. Depending on the size of the shock, this might also occur by a substantive amount. Further, monetary policy moves inflation only with some lag, which gives rise to some persistence in the deviation from target. However, in order to maintain credibility in the overall target, a prolonged one-sided deviation should result in an enhanced effort by the central bank to restore the target (Roger and Stone, 2005). We thus think that the maximum duration of inflation outside the target range is a good proxy for the commitment to maintaining and defending the inflation target.

The first row of Figure 9 repeats the baseline results for output, prices, and the policy rate for comparison. The middle row contains the differential effects of soft IT versus all 
non-IT economies, and the last row those of hard IT against all non-IT regimes. The difference to non-targeters are most pronounced for hard targeters. For the response of GDP, there are almost no significant differences between how soft targeting and noninflation targeting economies whether large adverse shocks. For the price level and policy response, the baseline results are maintained in both cases. However, for soft IT the difference in the price level and policy response is statistically only borderline significant and the difference in the latter response is quantitatively also smaller. Together, the findings suggest that the baseline results are mostly driven by hard targeters and that it is the actual conduct of monetary policy that matters for successful macroeconomic stabilization.

\subsection{Controlling for other potential shock absorbers}

We now estimate modified versions of model (2) in order to control for alternative channels that potentially affect the response to natural disasters. We make two separate extensions. First, we add level and interaction terms that account for alternative country characteristic which might change the shock absorption. Second, we add tripleinteraction terms which allow testing whether there is a marginal effect of IT conditional on other country features. In the first approach, we extend (2) with a generic variable $W_{i, t-j}$ as follows and reduce the impulse horizon to three years to limit the number of additional parameters:

$$
\begin{aligned}
\Delta y_{i, t}= & c+\sum_{j=0}^{J}\left[\beta_{i} S_{i, t-j}+\gamma_{j} I T_{i, t-j} S_{i, t-j}+\delta_{j} I T_{i, t-j}+\tau_{j} W_{i, t-j} S_{i, t-j}+\lambda_{i, t-j} W_{i, t-j}\right] \\
& +\sum_{l=1}^{L} \mu_{l} \Delta y_{i, t-l}+\phi X_{i, t-4}+v_{i}+v_{Y}+\varepsilon_{i, t} .
\end{aligned}
$$

We first control for a number of geographical and other country characteristics. In row (2), we correct for the exchange rate regime, as Ramcharan (2007) shows that flexible exchange rates are conducive to shock abs orption. We use a dummy variable which is equal to one in case of a fixed exchange rate regime, and zero in case of flexible exchange rates. ${ }^{14}$ We report the difference in the estimated average first and second moment of GDP growth and inflation between targeting and non-inflation targeting regimes over the response horizon, and the corresponding t-statistics. In rows (3)-(8) we replace the exchange rate dummy with the unconditional frequency by which a country is hit by

\footnotetext{
14 We use the measure of Ilzetzki et al. (2017) and map their classification which describes exchange rate regimes on the interval $(1,6)$ into the exchange rate regime dummy variable according to Ramcharan (2007). Specifically, regimes $\leq 3$ are classified as fixed (dummy $=1$ ), while 4 and 6 are classified as flexible (dummy $=2)$. We exclude $5=$ freely falling from the sample.
} 
shocks, the size of a country in squared $\mathrm{km}$, the share of urban population, and dummies for islands, African and Latin American countries, respectively. These interaction terms capture geographic characteristics that potentially affect both the choice of the monetary regime and the response to the shock. In all specifications the level effects of IT hold, and the volatility effects remain mostly significant as well.

Second, we reconsider the question of whether the level of development or institutions matter for the results. In (9), we include an interaction between the shocks and GDP per capita in 1997Q1. This measure approximates the average degree of development of an economy and may affect the capabilities to adjust to natural disasters. In the following specifications (10)-(15), we employ six indices compiled by Kaufman, Kraay and Mastruzzi (2006) and available as Worldwide Governance Indicators of the World Bank that measure the quality of governance and institutions. These indicators are shown to matter for procyclical fiscal spending(Alesina et al., 2008). In model (16), we alternatively interact the Polity IV variable, which is already contained in the baseline model in levels, with the shocks. Across models, the level effects of IT all survive, while the volatility effects tend to partially vanish.

Third, we correct for the behavior of fiscal policy and other financial capacities to provide assistance, as there is evidence that the introduction of IT might be particularly beneficial when combined with fiscal rules (Combes et al., 2017). In (17)-(20) we include as interactions the number of local, federal, and all fiscal rules ${ }^{15}$ from the IMF's fiscal rules dataset (Schaechter et al., 2012), as well as the size of the government, respectively. In the remaining rows we control for capital openness using the measure by Chinn and Ito (2008), trade openness measured as the sum of exports and imports over GDP, the level of the current account, and GDP size as alternative ways for a country to externally obtain or internally provide assistance to disaster-hit regions. Across these rows, all the results hold, irrespective of whether we look at the level or volatility impact of IT.

In the last row we include several of the control interaction terms simultaneously. Specifically, we combine one measure of development (GDP p.c.) with the exchange rate regime dummy, the frequency, the island dummy, and one size measure (size in $\mathrm{km}^{2}$ ). Given the large number of additional parameters, we reduce the impulse horizon to two years. The estimated effect of IT on first moments is smaller but significant. The impact on second moments is mixed. All in all, we thus conclude that while other factors also play a

${ }^{15}$ We construct a variable that takes the value one whenever there exists an expenditure, revenue, deficit, or debt rule. 
role in the absorption of shocks, they are not the main explanation for the differential responses between targeting and non-inflation targeting economies.

Table 3: Controlling for other shock absorbers

\begin{tabular}{|c|c|c|c|c|c|c|c|c|c|}
\hline & & \multicolumn{4}{|c|}{ Difference mean } & \multicolumn{4}{|c|}{ difference standard deviation } \\
\hline \multirow{2}{*}{\multicolumn{2}{|c|}{ Specification }} & \multicolumn{2}{|c|}{ D.GDP } & \multicolumn{2}{|c|}{ D.Prices } & \multicolumn{2}{|c|}{ D.GDP } & \multicolumn{2}{|c|}{ D.Prices } \\
\hline & & Effect IT & t-stat & Effect IT & t-stat & Effect IT & t-stat & Effect IT & t-stat \\
\hline \multirow[t]{2}{*}{$(1)$} & Baseline & 0.16 & 51.62 & -0.44 & -40.9 & -0.12 & -46.99 & -0.30 & -64.52 \\
\hline & \multicolumn{9}{|c|}{ Geographical and other country characteristics } \\
\hline$(2)$ & FX regime & 0.16 & 44.91 & -0.69 & -50.75 & -0.16 & -51.15 & -0.34 & -48.00 \\
\hline$(3)$ & Frequency & 0.12 & 33.35 & -0.49 & -37.65 & -0.21 & -54.01 & -0.37 & -54.39 \\
\hline$(4)$ & Size $(\mathrm{km} 2)$ & 0.15 & 48.64 & -0.51 & -44.71 & -0.09 & -28.95 & -0.22 & -41.91 \\
\hline$(5)$ & Urban pop. & 0.14 & 27.26 & -0.34 & -18.41 & 0.28 & 56.64 & 0.20 & 18.18 \\
\hline$(6)$ & Island & 0.14 & 41.84 & -0.61 & -51.34 & -0.15 & -49.51 & -0.28 & -44.10 \\
\hline$(7)$ & Africa & 0.16 & 49.78 & -0.51 & -43.95 & -0.12 & -38.90 & -0.21 & -39.18 \\
\hline \multirow[t]{2}{*}{$(8)$} & Latin Am. & 0.09 & 21.23 & -0.66 & -45.97 & 0.13 & 31.60 & -0.07 & -8.42 \\
\hline & \multicolumn{9}{|c|}{ Level of development and institutions } \\
\hline (9) & GDP p.c. & 0.17 & 50.29 & -0.65 & -48.58 & -0.19 & -54.92 & -0.39 & -52.51 \\
\hline$(10)$ & Gov. effect. & 0.07 & 12.56 & -0.21 & -10.52 & 0.01 & 2.06 & -0.04 & -3.97 \\
\hline (11) & Regul. qual. & 0.06 & 8.92 & -0.27 & -12.76 & 0.12 & 19.60 & 0.02 & 1.71 \\
\hline$(12)$ & Voice & 0.11 & 19.74 & -0.14 & -8.43 & 0.04 & 8.08 & -0.02 & -1.28 \\
\hline (13) & Rule law & 0.04 & 6.95 & -0.19 & -9.98 & -0.04 & -8.61 & -0.05 & -4.20 \\
\hline$(14)$ & Polit. stab. & 0.07 & 16.92 & -0.19 & -11.05 & -0.15 & -34.66 & -0.17 & -20.13 \\
\hline$(15)$ & Corruption & 0.06 & 10.29 & -0.29 & -15.53 & 0.03 & 4.89 & 0.00 & 0.17 \\
\hline \multirow[t]{2}{*}{$(16)$} & Democracy & 0.14 & 41.77 & -0.60 & -47.64 & 0.16 & 35.64 & 0.21 & 23.40 \\
\hline & \multicolumn{9}{|c|}{ Fiscal and financial capacity } \\
\hline (17) & Local rules & 0.21 & 47.14 & -0.47 & -30.69 & -0.18 & -55.07 & -0.50 & -56.34 \\
\hline$(18)$ & Nat. rules & 0.17 & 35.10 & -0.07 & -5.18 & -0.03 & -8.40 & -0.27 & -27.13 \\
\hline (19) & All rules & 0.19 & 40.76 & -0.35 & -24.85 & -0.11 & -29.06 & -0.45 & -46.39 \\
\hline$(20)$ & Gov. size & 0.20 & 46.48 & -0.56 & -38.62 & -0.23 & -59.98 & -0.38 & -45.17 \\
\hline (21) & Capital open. & 0.09 & 25.86 & -0.12 & -10.47 & -0.10 & -25.28 & -0.04 & -4.77 \\
\hline$(22)$ & Trade open. & 0.22 & 55.98 & -0.59 & -47.42 & -0.18 & -55.25 & -0.35 & -49.72 \\
\hline (23) & Current acc. & 0.21 & 42.12 & -0.80 & -52.90 & -0.09 & -26.49 & -0.13 & -21.22 \\
\hline \multirow[t]{2}{*}{ (24) } & GDP size & 0.11 & 35.31 & -0.71 & -56.16 & -0.16 & -51.63 & -0.36 & -51.47 \\
\hline & \multicolumn{9}{|c|}{$\underline{\text { Selected shock absorbers combined }}$} \\
\hline$(25)$ & Combined & 0.08 & 7.63 & -0.19 & -6.00 & 0.14 & 10.51 & -0.19 & -6.77 \\
\hline
\end{tabular}

Notes: The table shows the difference between the average estimated mean and standard deviation of GDP growth and inflation over three years following a large real shock in inflation targeting and non-inflation targeting economies, together with their t-statistics based on 500 Monte Carlo draws and when controlling for other potential shock absorbers. 


\section{Conclusions}

We present robust empirical evidence for the hypothesis that inflation targeting leads to better economic outcomes. When hit by large adverse shocks in the form of natural disasters, economies with an inflation targeting regime experience significantly lower inflation and inflation variability than under alternative monetary policy regimes. At the same time they enjoy higher and more stable output growth. The results are robust to a number of checks, in particular if we control for the quality of institutions and the presence of fiscal rules. The success of inflation targeting rests on a number of pillars.

First, predominantly hard targeting stabilizes the economy, while soft targeting has only limited effects. Second, a tougher stance on inflation does not only reduce consumer price fluctuations but also real exchange rate movements, which translates into a better adjustment through the external sector. Third, the findings indicate that IT, by reducing also the volatility of public and private interest rates, increases the effectiveness of monetary policy by lowering credit risk and term premia. Finally, the adoption of IT with its focus on price stability appears to be coupled with a stronger orientation of fiscal policy towards output stabilization. All in all, our findings show that inflation targeting is well and alive and rationalize the remarkable success of this monetary regime which, once adopted, has never been abandoned (Rose, 2007; 2014).

The paper contributes to the literature by analyzing the different economic outcomes under alternative monetary policy regimes conditional on large natural disasters, which are exogenous to the choice of the monetary regime. This approach to the question is novel as the existing literature has focused on the unconditional effects of inflation targeting (Walsh, 2009; Ball, 2010). The departure from looking at the average effect also explains why OECD member countries in the sample are benefitting more from IT than non-OECD countries, since the former are more often in the hard-IT group.

The findings of the paper have a number of implications for central banks. They show that while IT may not strictly be a superior policy mandate in open economies in normal or tranquil times - as shown by the existing literature - it is a better mandate in crisis times, at least when the domestic economy is hit by a large real shock, such as a natural catastrophe. The better adjustment to large disasters suggests that IT has been more of a savior during the Global Financial Crisis than thought. However, this holds only if a central bank does not merely pretend to follow an IT strategy, but if it has gained credibility through a successful track record on IT. Therefore, it should be considered in 
the debate on reforming the present IT frameworks toward more flexibility that allowing for prolonged deviations from the target range can come at a cost in terms of lower shock resilience.

\section{REFERENCES}

Alesina, A., F. R. Campante and G. Tabellini (2008). 'Why is fiscal policy often procyclical?', Journal of the European Economic Association, 6(5), 1006-1036.

Andersen, T. B., N. Malchow-Møller and J. Nordvig (2015). 'Inflation targeting and macroeconomic performance since the Great Recession', Oxford Economic Papers, 67(3), 598-613.

Ball, L. (2010). 'The Performance of Alternative Monetary Regimes', in B.M. Friedman and M. Woodford, Eds, Handbook of Monetary Economics, Vol. 3B, Amsterdam: Elsevier. 13031343.

Ball, L. M. and N. Sheridan (2004). 'Does inflation targeting matter?', in B. Bernanke and M. Woodford, Eds, The Inflation-Targeting Debate, NBER, University of Chicago Press, 249282.

Benson, C. and E. J. Clay (2004). Understanding the economic and financial impacts of natural disasters: World Bank Publications, Disaster Risk Management Series, No. 4.

Bernanke, B. S. and F. S. Mishkin (1997). 'Inflation Targeting: A New Framework for Monetary Policy?', Journal of Economic Perspectives, 11(2), 97-116.

Borio, C. (2014). 'Monetary policy and financial stability: What role in prevention and recovery?', BIS Working Papers, No. 440.

Brito, R. D. (2010). 'Inflation targeting does not matter: another look at OECD sacrifice ratios', Journal of Money, Credit and Banking, 42(8), 1679-1688.

Carvalho Filho, I. E. (2010). 'Inflation targeting and the crisis: An empirical assessment', IMF Working Papers, WP/10/45.

Cavallo, E., S. Galiani, I. Noy and J. Pantano (2013). 'Catastrophic natural disasters and economic growth', Review of Economics and Statistics, 95(5), 1549-1561.

Cecchetti, S. G. and R. W. Rich (2001). 'Structural estimates of the US sacrifice ratio', Journal of Business \& Economic Statistics, 19(4), 416-427.

Clarida, R., J. Gali and M. Gertler (1999) 'The science of monetary policy: a new Keynesian perspective', Journal of Economic Literature, 37, 1661-1707.

Combes, J. L., X. Debrun, A. Minea and R. Tapsoba (2017). 'Inflation Targeting, Fiscal Rules, and the Policy Mix: Cross-Effects and Interactions', Economic Journal, Nov. 2017,

De Mendonça, H. F. and G. J. d. G. e Souza (2012). 'Is inflation targeting a good remedy to control inflation?', Journal of Development economics, 98(2), 178-191.

Felbermayr, G. and J. Gröschl (2014). 'Naturally negative: The growth effects of natural disasters', Journal of Development economics, Vol. 111, 92-106.

Frankel, J. (2012). 'The death of inflation targeting', VoxEU. org, 19 June 2012.

Friedman, B. M. (2004). 'Why the Federal Reserve should not adopt inflation targeting', International Finance, 7(1), 129-136.

Gonçalves, C. E. S. and A. Carvalho (2009). 'Inflation targeting matters: evidence from OECD economies' sacrifice ratios', Journal of Money, Credit and Banking, 41(1), 233-243.

Hallegatte, S. and P. Dumas (2009). 'Can natural disasters have positive consequences? Investigating the role of embodied technical change', Ecological Economics, 68(3), 777786. 
Inoue, H. and Y. Todo (2017). 'Propagation of negative shocks through firm networks: evidence from simulation on comprehensive supply-chain data', RIETI Discussion Paper Series, 17-E-044.

Judson, R. A. and A. L. Owen (1999). 'Estimating dynamic panel data models: A guide for macroeconomists', Economics Letters, 65(1), 9-15.

Keen, B. D. and M. R. Pakko (2011). 'Monetary Policy and Natural Disasters in a DSGE model', Southern Economic Journal, 77(4), 973-990.

Kilian, L. (2008). 'Exogenous oil supply shocks: how big are they and how much do they matter for the US economy?', The Review of Economics and Statistics, 90(2), 216-240.

Kim, J. (2011). 'Inflation Targeting as Constrained Discretion', Journal of Money, Credit and Banking, 43(7), 1505-1522.

Kousky, C. (2014). 'Informing climate adaptation: A review of the economic costs of natural disasters', Energy Economics, Vol. 46, 576-592.

Kydland, F. E. and E. C. Prescott (1977). 'Rules rather than discretion: The inconsistency of optimal plans', Journal of Political Economy, 85(3), 473-491.

Lin, S. (2010). 'On the international effects of inflation targeting', The Review of Economics and Statistics, 92(1), 195-199.

Lin, S. and H. Ye (2007). 'Does inflation targeting really make a difference? Evaluating the treatment effect of inflation targeting in seven industrial countries', Journal of Monetary Economics, 54(8), 2521-2533.

Lin, S. and H. Ye (2009). 'Does inflation targeting make a difference in developing countries?', Journal of Development economics, 89(1), 118-123.

Liu, Z., D. F. Waggoner and T. Zha (2011). 'Sources of macroeconomic fluctuations: A regimeswitching DSGE approach', Quantitative Economics, 2(2), 251-301.

Loayza, N. V., E. Olaberria, J. Rigolini and L. Christiaensen (2012). 'Natural disasters and growth: Going beyond the averages', World Development, 40(7), 1317-1336.

Nickell, S. (1981). 'Biases in Dynamic Models with Fixed Effects', Econometrica, 49(6), 1417 1426.

Noy, I. (2009). 'The macroeconomic consequences of disasters', Journal of Development Economics, 88(2), 221-231.

Ramcharan, R. (2007). 'Does the exchange rate regime matter for real shocks? Evidence from windstorms and earthquakes', Journal of International Economics, 73(1), 31-47.

Roger, S. (2009). 'Inflation Targeting at 20: Achievements and Challenges', IMF Working Papers, WP/09/236.

Roger, S. and M. Stone (2005) 'On Target? the International Experience with Achieving Inflation Targets', IMF Working Papers, WP/05/163.

Romer, D. (2006). Advanced macroeconomics, $3^{\text {rd }}$ Edition, McGraw-Hill Companies: New York.

Rose, A. K. (2007). 'A stable international monetary system emerges: Inflation targeting is Bretton Woods, reversed', Journal of International Money and Finance, 26(5), 663-681.

Rose, A. K. (2014). 'Surprising similarities: recent monetary regimes of small economies', Journal of International Money and Finance, Vol. 49, 5-27.

Schaechter, A., T. Kinda, N. Budina and A. Weber (2012). 'Fiscal rules in response to the crisis-toward the'next-generation'rules: A new dataset', IMF Working Papers, WP/12-187.

Skidmore, M. and H. Toya (2002). 'Do natural disasters promote long-run growth?', Economic Inquiry, 40(4), 664-687.

Solow, R. M. (1956). 'A contribution to the theory of economic growth', The Quarterly Journal of Economics, 70(1), 65-94.

Stiglitz, J. E. (2008). 'The failure of inflation targeting', Project Syndicate, May 6, 2008. 
Strulik, H. and T. Trimborn (2014) 'Natural disasters and macroeconomic performance: The role of residential investment', University of Goettingen, CEGE Discussion Papers, No. 194.

Svensson, L. E. (2009). 'Flexible inflation targeting: Lessons from the financial crisis', BIS Review, 112/2009.

Svensson, L. E. (2010). 'Inflation Targeting', in B.M. Friedman and M. Woodford, Eds, Handbook of Monetary Economics, Vol. 3. Elsevier, 1237-1302.

Taylor, J. B. (2007). 'Housing and Monetary Policy' in: Proceedings - Economic Policy Symposium, Jacksohn Hole, Federal Reserve Bank of Kansas City, 463-476.

Vega, M. and D. Winkelried (2005). 'Inflation targeting and inflation behavior: a successful story?', International Journal of Central Banking, 1(3), 153-175.

Walsh, C. E. (2009). 'Inflation targeting: What have we learned?', International Finance, 12(2), 195-233. 


\section{ONLINE APPENDiX — Not FOR PUBliCATION}

This Online Appendix contains supplementary material for the paper "Inflation Targeting as a Shock Absorber", by Marcel Fratzscher, Christoph Große Steffen, and Malte Rieth.

\section{Further sensitivity analysis}

\section{I.a. Alternative lag length selection and estimator}

We evaluate whether the choice of the lag length of the endogenous variables or the choice of the estimator changes our main conclusions. The first sensitivity test is motivated by Coibion (2012), who shows that the size of the effects of monetary policy estimated by Romer and Romer (2004) depends, among others, on the number of lags of the endogenous variables. Figure I.1 shows the differential response of output, prices, and the policy rate between targeting and non-inflation targeting regimes. The first row contains the results when including three lags of the endogenous variables, instead of four lags as in the baseline specification. The difference in the effects of IT is qualitatively not and quantitatively as well as in terms of statistical significance only mildly affected by this change of the model. We obtain similar results when reducing the number of lags to two in the next row.

The second sensitivity tests use alternative estimators to address remaining concerns about biased estimates when using fixed-effects and lagged endogenous variables as regressors (Nickell, 1981), although this bias is known to be small in samples where the time-dimension is long ( $T>30$, Judson and Owen, 1999), as in our case. In the third row, we explicitly model the error term structure using panel corrected standard errors, following Beck and Katz (1995). The error structure accounts for panel heteroskedasticity and contemporaneously as well as serially correlated errors. Panel heteroskedasticity and contemporaneous correlation can arise in large cross-country panels where the level of the endogenous variables differs across countries and where countries are potentially affected by correlated shocks. In row four, we instead use feasible generalized least squares estimation with heteroskedastic and first-order autocorrelated errors. In both cases, we include a full set of country dummies. In the 
final row, we return to the within-transformation, but model the autocorrelation in the error term. In all three cases we report the point estimates together with their 90 percent asymptotic standard errors. All in all, using these alternative estimators does not change our main results. The differential responses are qualitatively and quantitatively similar to the baseline results.

Figure I.1: Alternative lag length and estimator
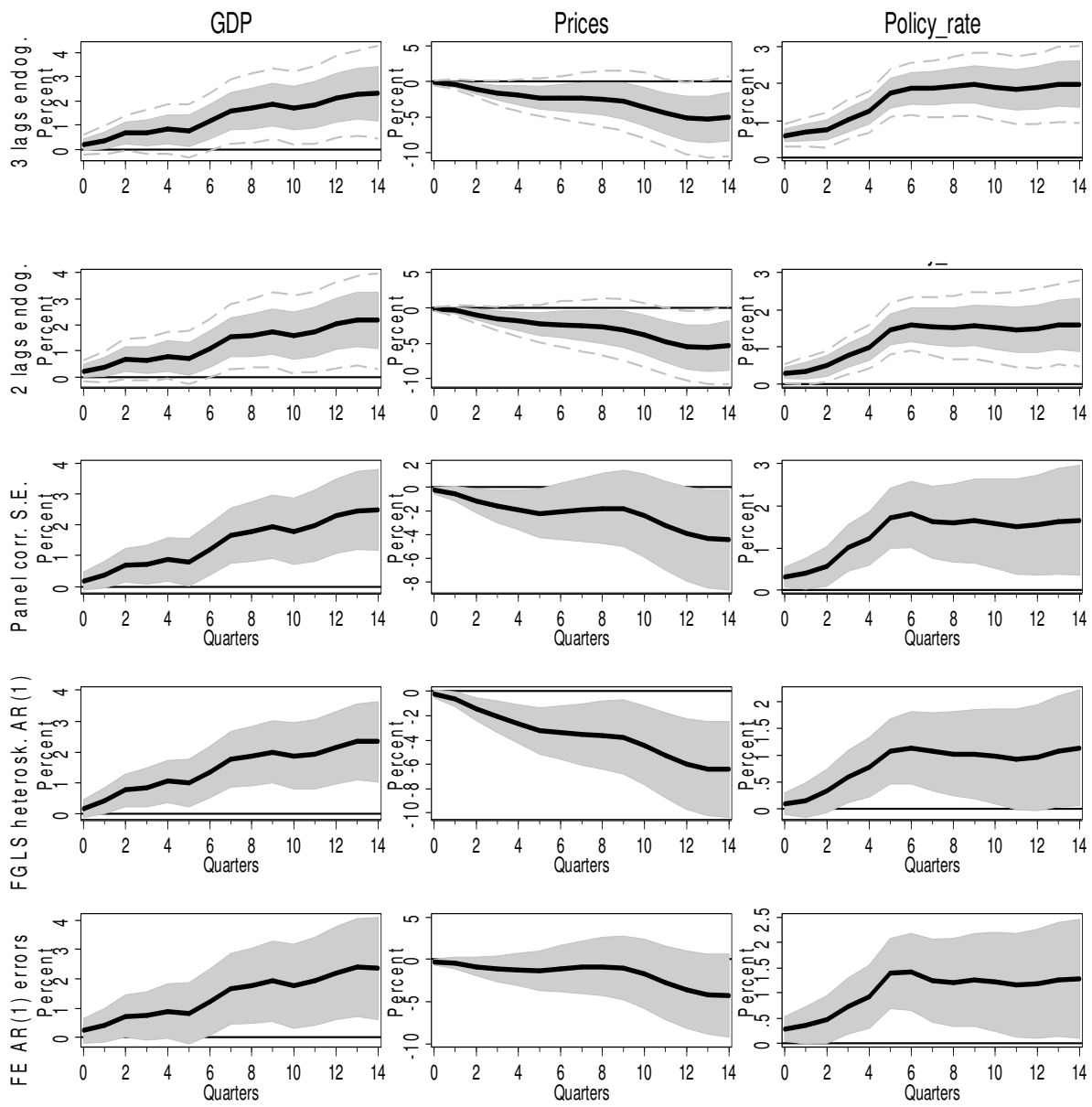

Note: The figure shows the difference between the responses of inflation targeting and non-inflation targeting countries to large natural disasters based on alternative number of lags of the endogenous variable (row 1 - two lags, row 2 - three lags; 68 and 90 percent confidence bands based on 500 Monte-Carlo draws) and based on alternative estimators (row 3 - panel corrected standard errors, row - 4 fixed-effects with AR(1) error terms, row 5 - feasible generalized least squares with heteroskedastic cross-sectional and first-order auto-correlated errors; all with 90 percent asymptotic confidence bands). 


\section{I.b. Alternative shock selection and modified classification of inflation targeters}

We now assess whether the main results are sensitive to the definition of shocks or inflation targeting. Figure I.2 shows the differential effects across targeting and noninflation targeting economies of large disasters on output, prices, and the policy rate. The first row is based on a subset of the shocks considered in the main analysis. Specifically, we use only the upper $75^{\text {th }}$ percentile of the damage variable, instead of the upper $50^{\text {th }}$ percentile in the baseline specification, and from those select the bottom $50^{\text {th }}$ percentile of GDP deviations, as before. This choice leaves us with 57 shocks under IT and 23 shocks otherwise. By focusing on even larger disasters, we aim at further eliminating noise in damage reporting. The first row shows that the differential effects tend to be similar to the baseline results. Next, we keep the upper $75^{\text {th }}$ percentile of the damage variable, but leave out the second step in the selection procedure to see whether not conditioning on GDP drops changes the results. In this case, we obtain 112 shocks for non-inflation targeters and 49 shocks for targeters. The second row shows that the differential effects of IT are qualitatively unaffected.

Next, we test whether the weighting of disasters by the onset month affects the main results. In the third row we use unweighted damages to construct the shocks, whereas in the fourth row we weigh the reported damage by the onset month, as before, but additionally take into account up to two months of spillovers in the next quarter. In the first case, the estimation precision tends to decrease, while it tends to increase in the second. In both cases, the main results are retained. Last, we use an alternative classification of IT countries as there is no consensus in the literature whether the ECB is an inflation targeter nor not (Ball, 2010; Rose, 2014). We thus re-define all 18 euro area countries as non-inflation targeters, different to the baseline classification where all countries are coded as targeters when entering the euro. The bottom row shows that the results are mostly unchanged. 
Figure I.2: Alternative shock definition and classification of inflation targeters

GDP
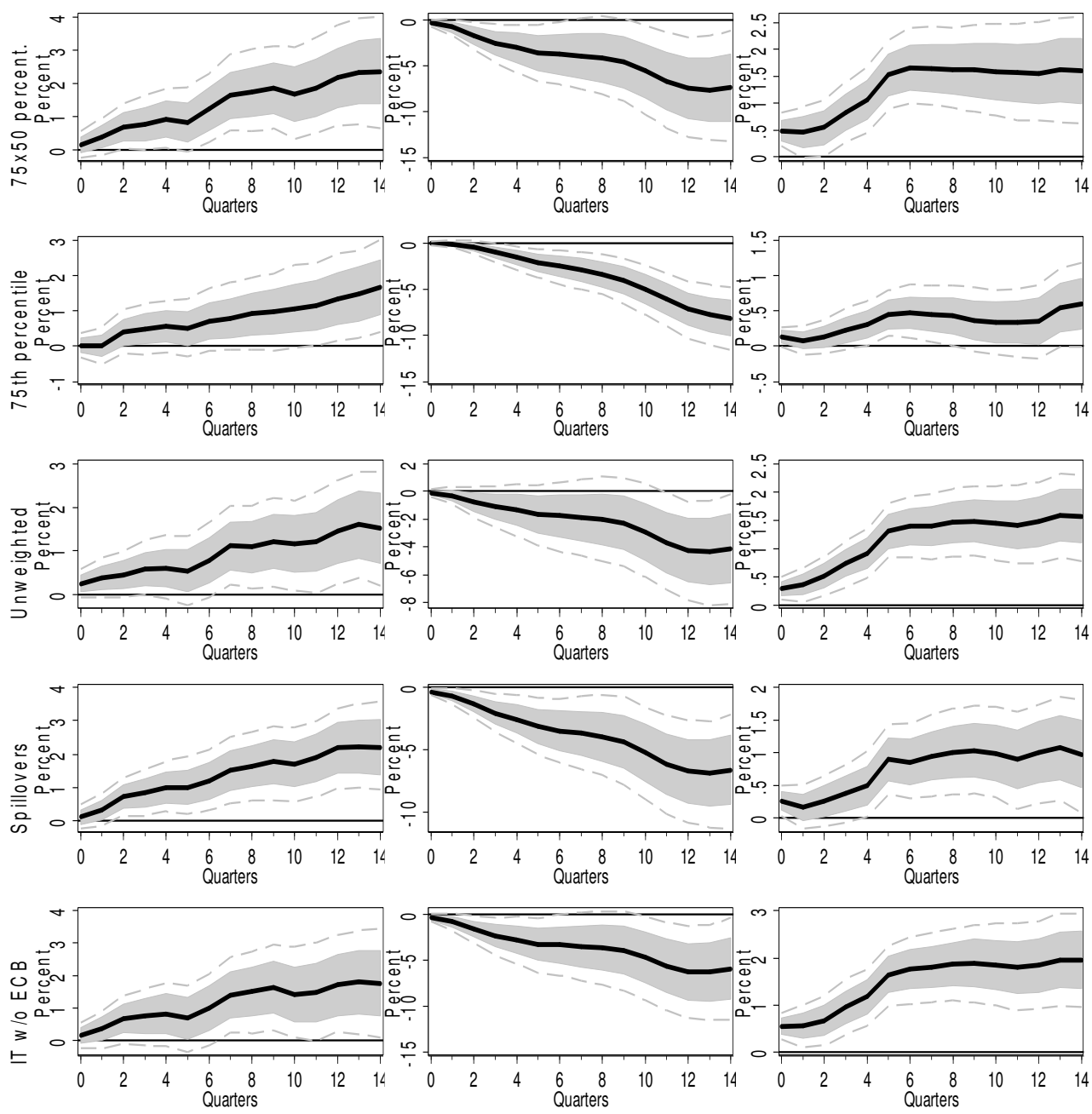

Note: The figure shows the difference between the responses of inflation targeting and non-inflation targeting countries to large natural disasters based on alternative selections of the shocks (first two rows) and a modified definition of IT (last row). The econometric model follows equation (2) in the main text. Confidence bands refer to the 68 and 90 percent level and are based on 500 Monte-Carlo draws.

\section{I.c. Triple-interaction effects}

As a last set of robustness checks, we run the following model with a triple-interaction term between the shock, the IT dummy, and a third variable:

$$
\begin{aligned}
\Delta y_{i, t}=c+\sum_{j=0}^{J}\left[\beta_{i} S_{i, t-j}\right. & +\gamma_{j} I T_{i, t-j} S_{i, t-j}+\delta_{j} I T_{i, t-j}+\tau_{j} W_{i, t-j} S_{i, t-j}+\lambda_{i, t-j} W_{i, t-j} \\
& \left.+\rho_{j} I T_{i, t-j} W_{i, t-j}+\xi_{i, t-j} I T_{i, t-j} W_{i, t-j} S_{i, t-j}\right] \\
& +\sum_{l=1}^{L} \mu_{l} \Delta y_{i, t-l}+\phi X_{i, t-4}+v_{i}+v_{Y}+\varepsilon_{i, t}
\end{aligned}
$$


The focus is on the coefficients of the triple-interaction $\xi_{i, t-j}$. These estimates capture the marginal effect of inflation targeting that arises due to positive or negative synergies of this monetary regime with other country characteristics. The results are shown in cumulative terms in Figure I.3. As the number of coefficients to be estimated in model (5) increases by two times $J$, we set $J=11$.

Row (1) depicts a case where $W_{i, t-j}$ is set to the exchange rate regime. ${ }^{1}$ There has been recently renewed interest in the question whether inflation targeting countries should also let their currencies float freely, or whether it is beneficial for them to intervene through sterilized trades in order to reduce exchange rate volatility (Ghosh et al., 2016). The rationale behind the use of targeted interventions in the foreign exchange market for IT countries is that this additional instrument can support financial stability in the presence of unhedged exposure to foreign currency of domestic firms. Ebeke and Fouejieu (2015) document that there is cross-country heterogeneity with respect to the exchange rate regime depending on the exposure to foreign exchange risk.

Rows (2) and (3) feature cases where the triple-interaction is constructed with a G7 and OECD dummy, respectively. These are variations of the previous hypothesis that the level of development is important for the macroeconomic benefits of IT. If the effect of IT on, say, GDP growth is larger in non-G7 countries than in this group, the cumulative triple-interaction terms would be significantly negative. In all three rows, the cumulative triple-interaction effects are largely insignificant. One exception is the policy rate in the case of a triple-interaction with the OECD dummy. The positive effect indicates that OECD countries that operate under IT raise rates more after large real shocks than nonOECD countries under IT.

${ }^{1}$ We used the indicator variable of Shambaugh (2004) who codes countries that de facto peg their currencies as a one. 
Figure I.3: Controlling for alternative potential shock absorbers
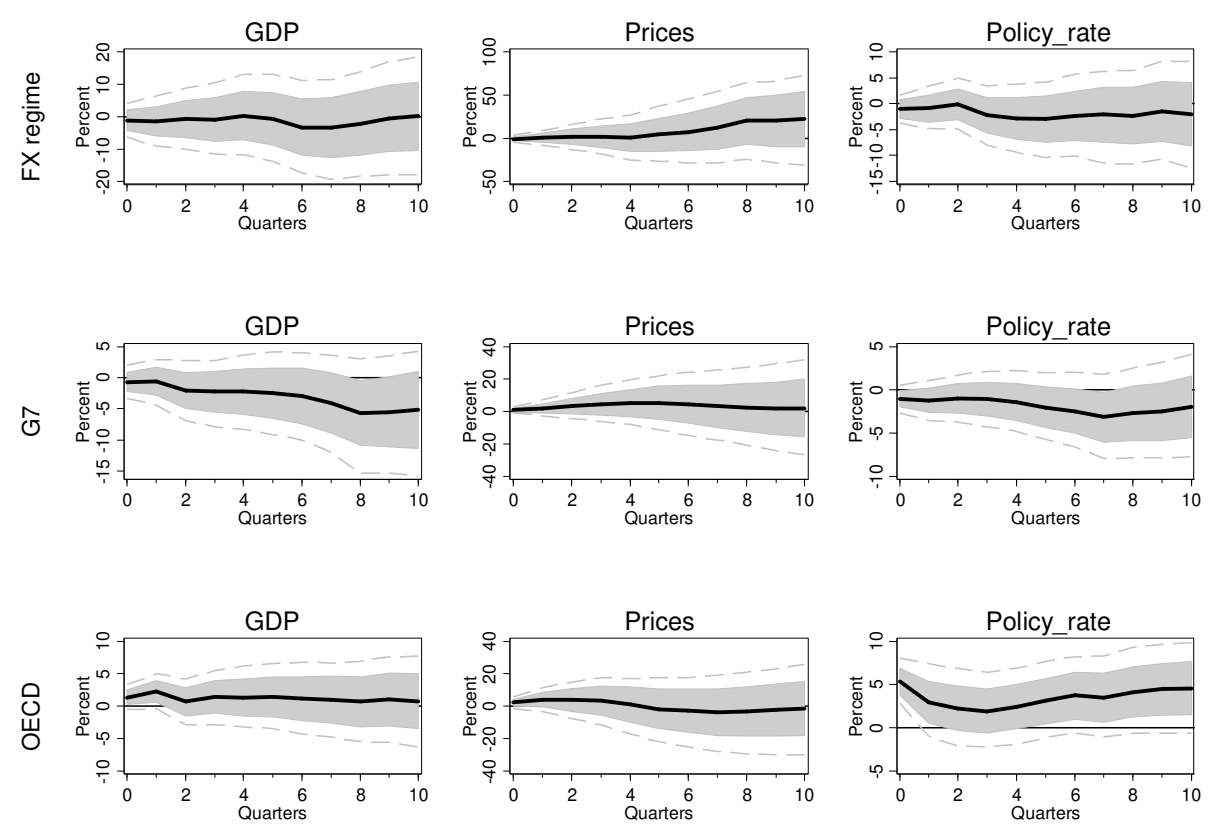

Note: The figure shows the cumulative coefficients of the triple interaction term in model (5) between inflation targeting and other potential shock absorbing country characteristics with large natural disaster shocks. Confidence bands refer to the 68 and 90 percent level and are based on 500 Monte-Carlo draws. 


\section{Supplementary Tables and Figures}

Table A1: Inflation targeting adoption dates

\begin{tabular}{|c|c|c|}
\hline Country & IT adoption date ${ }^{2}$ & euro adoption date \\
\hline Albania & January 2009 & \\
\hline Australia $^{1}$ & April 1993 & \\
\hline Brazil & June 1999 & \\
\hline Canada $^{1}$ & February 1991 & \\
\hline Chile $^{1}$ & September 1999 & \\
\hline Colombia & September 1999 & \\
\hline Czech Rep ${ }^{1}$ & December 1997 & \\
\hline Ghana & May 2007 & \\
\hline Guatemala & January 2005 & \\
\hline Hungary ${ }^{1}$ & June 2001 & \\
\hline Iceland $^{1}$ & March 2001 & \\
\hline Indonesia & July 2005 & \\
\hline Israel $^{1}$ & June 1997 & \\
\hline Korea Rep ${ }^{1}$ & January 2001 & \\
\hline Mexico $^{1}$ & January 2001 & \\
\hline New Zealand ${ }^{1}$ & January 1990 & \\
\hline Norway $^{1}$ & March 2001 & \\
\hline Peru & January 2002 & \\
\hline Philippines & January 2002 & \\
\hline Poland ${ }^{1}$ & December 1998 & \\
\hline Romania & August 2005 & \\
\hline Serbia & September 2006 & \\
\hline South Africa & February 2000 & \\
\hline Sweden ${ }^{1}$ & January 1993 & \\
\hline Thailand & May 2000 & \\
\hline Turkey $^{1}$ & January 2006 & \\
\hline United Kingdom $^{1}$ & December 1992 & \\
\hline Finland ${ }^{1}$ & February 1993 & January 1999 \\
\hline Slovakia $^{1}$ & January 2005 & January 2009 \\
\hline Spain ${ }^{1}$ & January 1995 & January 1999 \\
\hline Austria $^{1}$ & & January 1999 \\
\hline Belgium ${ }^{1}$ & & January 1999 \\
\hline Cyprus & & August 2008 \\
\hline Estonia $^{1}$ & & January 2011 \\
\hline France $^{1}$ & & January 1999 \\
\hline Germany $^{1}$ & & January 1999 \\
\hline Greece $^{1}$ & & January 2001 \\
\hline Ireland $^{1}$ & & January 1999 \\
\hline Italy ${ }^{1}$ & & January 1999 \\
\hline Latvia $^{1}$ & & January 2014 \\
\hline Lithuania & & January 2015 \\
\hline Luxembourg$^{1}$ & & January 1999 \\
\hline Malta & & January 2008 \\
\hline Netherlands ${ }^{1}$ & & January 1999 \\
\hline Portugal $^{1}$ & & January 1999 \\
\hline Slovenia ${ }^{1}$ & & January 2007 \\
\hline
\end{tabular}

Notes: ${ }^{1)}$ OECD member country. ${ }^{2)}$ Date of adopting fully fledged inflation targeting. Countries that introduced inflation targeting before entering the euro are coded as targeters from the initial adoption of inflation targeting onwards. Sources: Roger (2009), National central banks, European Central Bank. 
Table A2: Country list

\begin{tabular}{|c|c|c|}
\hline Albania & India & Pakistan \\
\hline Algeria & Indonesia & Peru \\
\hline Argentina & Ireland & Philippines \\
\hline Australia & Israel & Poland \\
\hline Austria & Italy & Portugal \\
\hline Belgium & Japan & Romania \\
\hline Brazil & Jordan & Russia \\
\hline Bulgaria & Kazakhstan & Serbia \\
\hline Canada & Kenya & Singapore \\
\hline Chile & Korea Rep & Slovakia \\
\hline Colombia & Kyrgyzstan & South Africa \\
\hline Croatia & Latvia & Spain \\
\hline Cyprus & Lithuania & Sri Lanka \\
\hline Czech Rep & Luxembourg & Sweden \\
\hline Denmark & Malaysia & Switzerland \\
\hline Egypt & Malta & Thailand \\
\hline Estonia & Mauritius & Trinidad and Tobago \\
\hline Finland & Mexico & Tunisia \\
\hline France & Mongolia & Turkey \\
\hline Georgia & Morocco & Ukraine \\
\hline Germany & Namibia & United Kingdom \\
\hline Greece & Netherlands & United States \\
\hline Guatemala & New Zealand & Viet Nam \\
\hline Honduras & Nigeria & Yemen \\
\hline Hungary & Norway & \\
\hline Iceland & Oman & \\
\hline
\end{tabular}

Notes: The table lists the countries included in the analysis. 
Table A3: Data sources

\begin{tabular}{|c|c|c|}
\hline Variable & Definition & Source \\
\hline DAMw50X50 & $\begin{array}{l}\text { Damage from disasters in } \% \text { of GDP: upper } 50^{\text {th }} \text { percentile of damage } \\
\text { reported, lower } 50 \text { th percentile of deviations from GDP per capita } \\
\text { trend growth rate }\end{array}$ & EM-DAT, IMF-IFS \\
\hline DAMw50 & $\begin{array}{l}\text { Damage from disasters in \% of GDP: upper } 50 \text { th percentile of damage } \\
\text { reported }\end{array}$ & $\begin{array}{l}\text { EM-DAT, IMF-IFS, OECD, National } \\
\text { Sources }\end{array}$ \\
\hline itecb & Dummy for inflation targeting, including the euro area & See Table A1 \\
\hline it & Dummy for inflation targeting & See Table A1 \\
\hline GDP & Real per capita GDP & OECD, national sources, WDI \\
\hline Prices & CPI price index, & IMF-IFS \\
\hline Policy rate & $\begin{array}{l}\text { Core rate at which banks can borrow from the national central } \\
\text { bank, end of period, percent }\end{array}$ & Datastream \\
\hline $\begin{array}{l}\text { Government } \\
\text { consumption }\end{array}$ & Real government consumption, seasonally adjusted & OECD, national sources \\
\hline Private consumption & Real private consumption, seasonally adjusted & OECD, national sources \\
\hline Investment & Gross capital formation, seasonally adjusted & OECD, national sources \\
\hline REER & Real effective exchange rate index & BIS \\
\hline Exports & Real exports, seasonally adjusted & OECD, national sources \\
\hline Imports & Real imports, seasonally adjusted & OECD, national sources \\
\hline Tbill rate & Yield on government bond, 3 month maturity, percent & Datastream \\
\hline Money rate & Money market rate, percent & IMF-IFS \\
\hline Lending rate & Lending rate, percent & IMF-IFS \\
\hline Long rate & Yield on long-term government bond, percent & IMF-IFS \\
\hline Democracy & $\begin{array}{l}\text { Polity IV, scaled and standardized on the interval }[0,1] \text {, } \\
\text { with } 1 \text { indicating a high level of democratic institutions }\end{array}$ & Center for Systemic Peace \\
\hline Urbanization & Urban population in percent of total population, annual frequency & World Bank/WDI \\
\hline Density & $\begin{array}{l}\text { Population (thousand) per land area (square kilometers), annual } \\
\text { frequency }\end{array}$ & World Bank/WDI \\
\hline $\begin{array}{l}\text { Capital account } \\
\text { Openness }\end{array}$ & Openness in capital account transactions & Chinn-Ito (2008) \\
\hline FX rate regime & Exchange rate arrangements & Ilzetzki et al. (2017) \\
\hline Currency peg & Exchange rates with a currency peg & Shambaugh (2004) \\
\hline Fiscal Rules & $\begin{array}{l}\text { Existence of fiscal rules, national or supranational, from the IMF Fiscal } \\
\text { Rules dataset }\end{array}$ & Schaechter et al. (2012) \\
\hline Institutional quality & $\begin{array}{l}\text { Six different indicators on the institutional quality, defined over the } \\
\text { interval }[-2.5,2.5] \text {, including (i) government effectiveness, (ii) } \\
\text { regulatory quality, (iii) voice and accountability, (iv) rule of law, (v) } \\
\text { political stability and absence of violence/terrorism, (vi) control of } \\
\text { corruption }\end{array}$ & $\begin{array}{l}\text { World Bank, The Worldwide } \\
\text { Governance Indicators, Kaufmann } \\
\text { et al. (2006) }\end{array}$ \\
\hline
\end{tabular}

Notes: The table lists the variables, definitions, and data sources used in the empirical analysis. 
Table A4: Probit estimates

\begin{tabular}{|c|c|c|c|c|c|}
\hline & (1) & (2) & (3) & (4) & (5) \\
\hline \multicolumn{6}{|c|}{ Dependent variable: inflation targeting } \\
\hline $\operatorname{Shock}(\mathrm{t})$ & 0.002 & -0.078 & -0.079 & -0.077 & -0.096 \\
\hline Shock(t-1) & 0.034 & -0.008 & -0.055 & -0.048 & -0.063 \\
\hline Shock(t-2) & 0.030 & -0.049 & -0.077 & -0.058 & -0.077 \\
\hline Shock(t-3) & 0.028 & -0.040 & -0.070 & -0.047 & -0.070 \\
\hline Shock(t-4) & 0.023 & -0.027 & -0.036 & -0.017 & -0.037 \\
\hline Shock(t-5) & 0.021 & -0.039 & -0.029 & -0.010 & -0.029 \\
\hline Shock(t-6) & 0.035 & 0.018 & 0.019 & 0.027 & 0.006 \\
\hline Shock(t-7) & 0.035 & -0.025 & -0.031 & -0.023 & -0.035 \\
\hline Shock(t-8) & 0.036 & -0.025 & -0.028 & -0.027 & -0.042 \\
\hline Shock(t-9) & 0.036 & -0.022 & -0.028 & -0.026 & -0.046 \\
\hline Shock(t-10) & 0.034 & -0.051 & -0.053 & -0.050 & -0.072 \\
\hline Shock(t-11) & 0.035 & -0.019 & -0.020 & -0.016 & -0.037 \\
\hline Shock(t-12) & 0.041 & 0.014 & 0.008 & 0.013 & -0.010 \\
\hline Shock(t-13) & 0.035 & -0.014 & -0.027 & -0.025 & -0.046 \\
\hline Shock(t-14) & 0.027 & -0.022 & -0.041 & -0.041 & -0.058 \\
\hline $\operatorname{Shock}(\mathrm{t}-15)$ & 0.012 & -0.050 & -0.056 & -0.060 & -0.077 \\
\hline Time-invariant characteristics & Yes & Yes & Yes & Yes & Yes \\
\hline Time-varying characteristics & Yes & Yes & Yes & Yes & Yes \\
\hline Lags 1 to 4 inflation & & Yes & Yes & Yes & Yes \\
\hline Lags 1 to 4 GDP growth & & & Yes & Yes & Yes \\
\hline Inflation volatility & & & & Yes & Yes \\
\hline GDP growth volatility & & & & & Yes \\
\hline Observations & 10550 & 4908 & 4295 & 4287 & 4254 \\
\hline Pseudo R-squared & 0.28 & 0.30 & 0.31 & 0.32 & 0.33 \\
\hline p-value F-test shocks & 0.999 & 1.000 & 0.995 & 0.999 & 0.975 \\
\hline
\end{tabular}

Notes: The table shows estimated probit models where the dependent variable is the probability of a country to target inflation. The explanatory variables are natural disaster shocks (lag 0 to 15) and other control variables. Time-invariant characteristics include the number of shocks per country in the sample, the cumulative damage of these shocks per country, per capita GDP in 1997, a dummy variable indicating African countries, and a dummy for islands. Time-varying characteristics contain lag 4 of democracy, the share of urban population, density, country size, and population, respectively. Inflation and GDP growth volatility are measured as the rolling realized variances of these variables over both four and eight quarters. Statistical significance is based on robust standard errors and would be indicated by stars. The shocks are not significant, however, at any lag length. The bottom row of the table shows the p-value of the F-test for joint significance of all lags. 
Figure A1: Empirical density function for estimated mean output growth and inflation
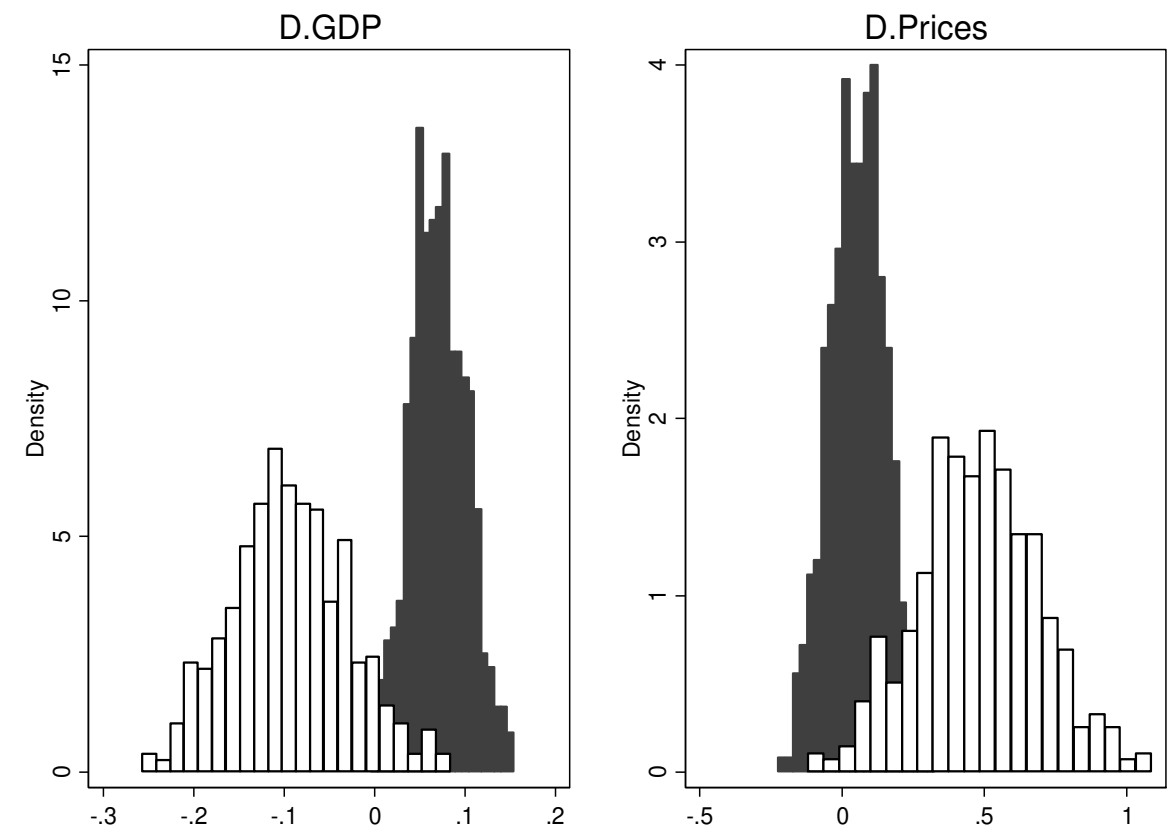

Note: The figure shows the simulated density function of mean output growth and mean inflation over a horizon of four years following a large natural disaster in inflation targeting (black bars) and non-inflation targeting economies (white bars).

Figure A2: Empirical density functions for estimated standard deviations
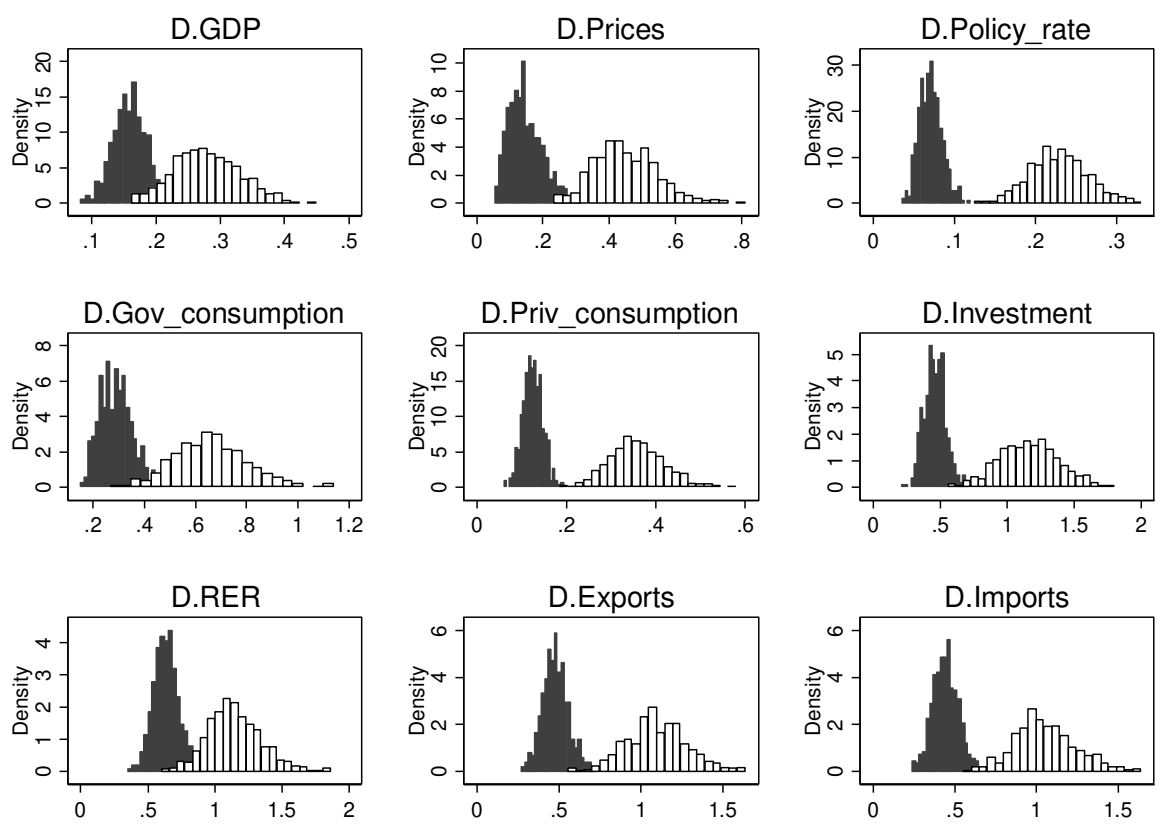

Note: The figure shows the simulated density function of the standard deviations of selected macroeconomic variables over a horizon of four years following a large natural disaster in inflation targeting (black bars) and non-inflation targeting economies (white bars). 
Figure A3: Response of monetary policy and interest rates to large natural disasters in targeting and non-inflation targeting economies
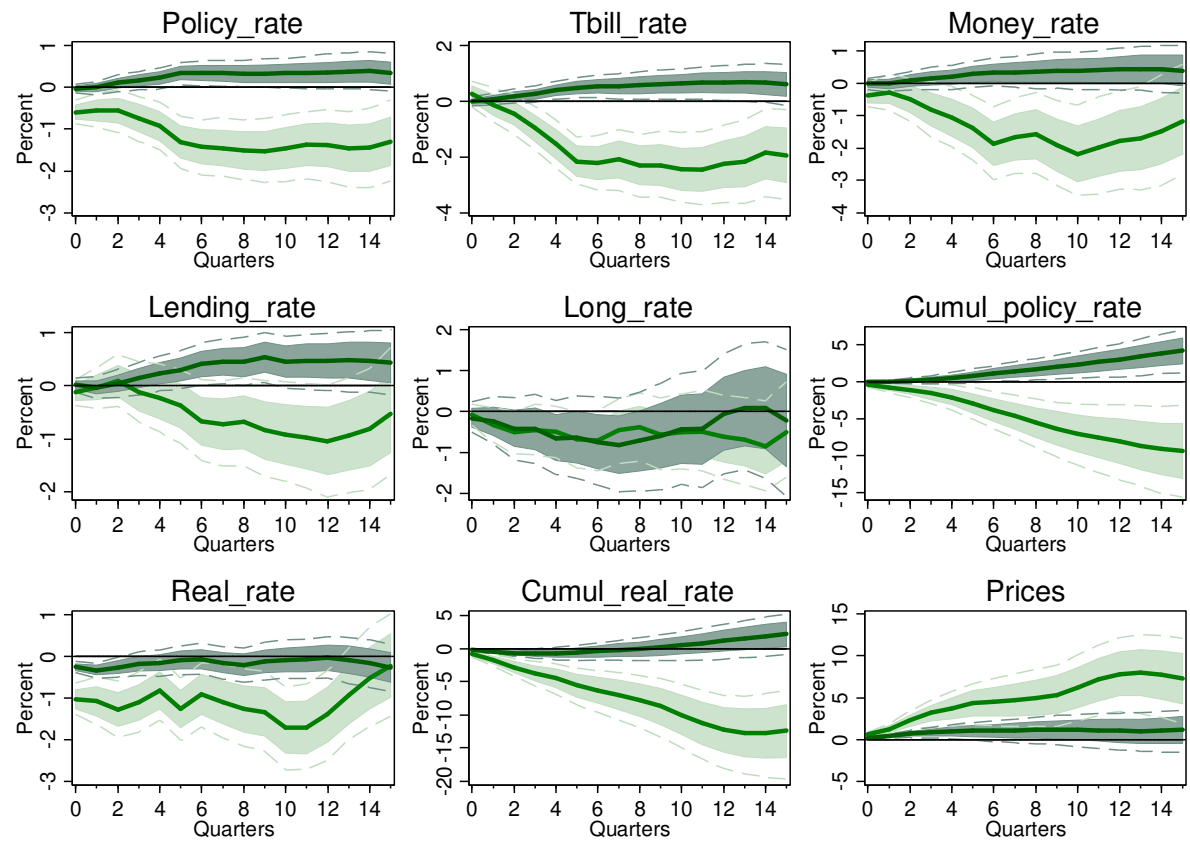

Note: The figure shows the response of the level (cumulated first difference) of interest rate variables in both targeting (dark shaded area) and non-inflation targeting economies(light shaded area) to large natural disasters over the period 1970Q1-2015Q4. Confidence bands refer to the 68 and 90 percent level and are based on 500 Monte-Carlo draws. 
Figure A4: Inflation and targets in euro area countries
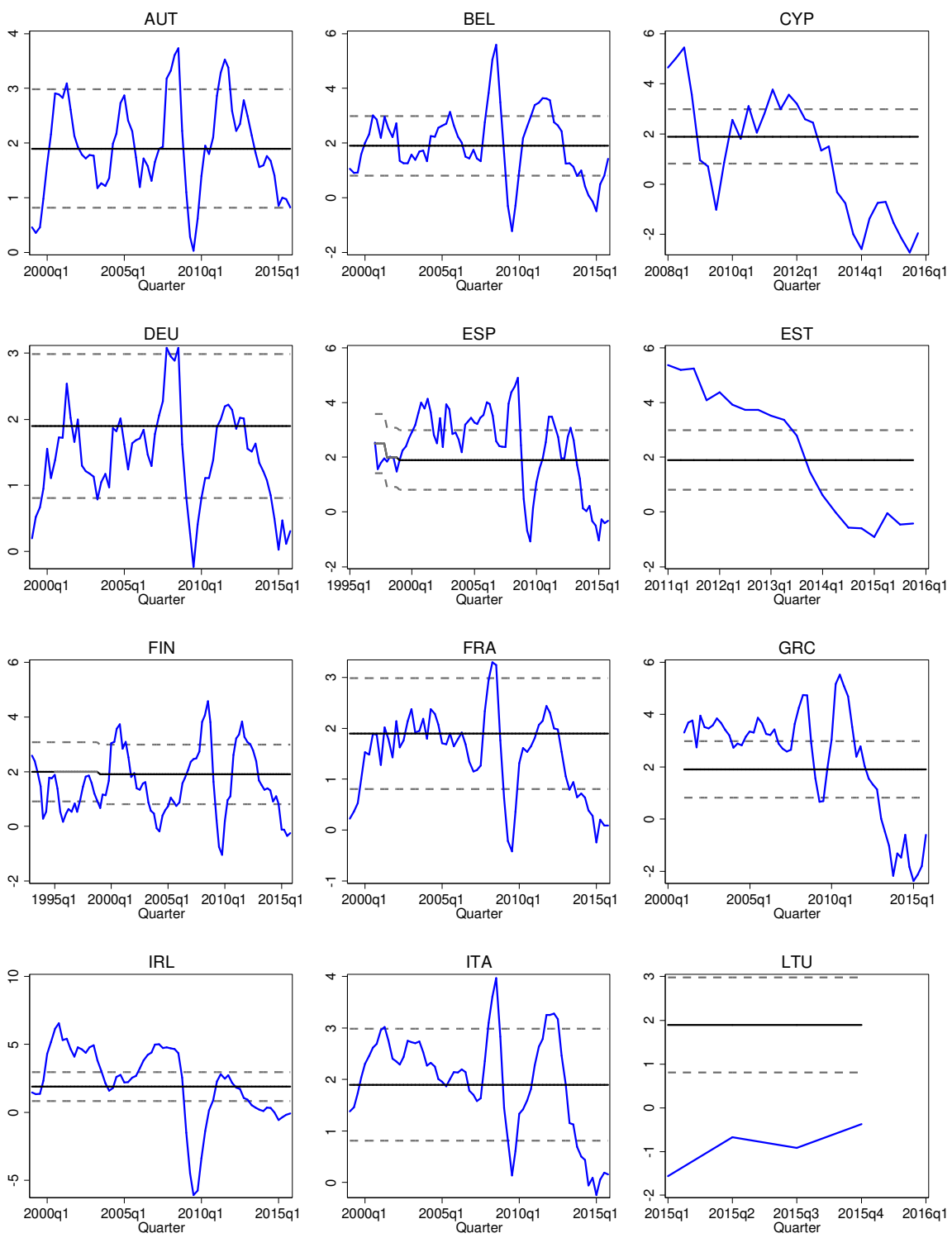

[Continued on next page] 
[Figure A4: Inflation and targets in euro area countries] continued
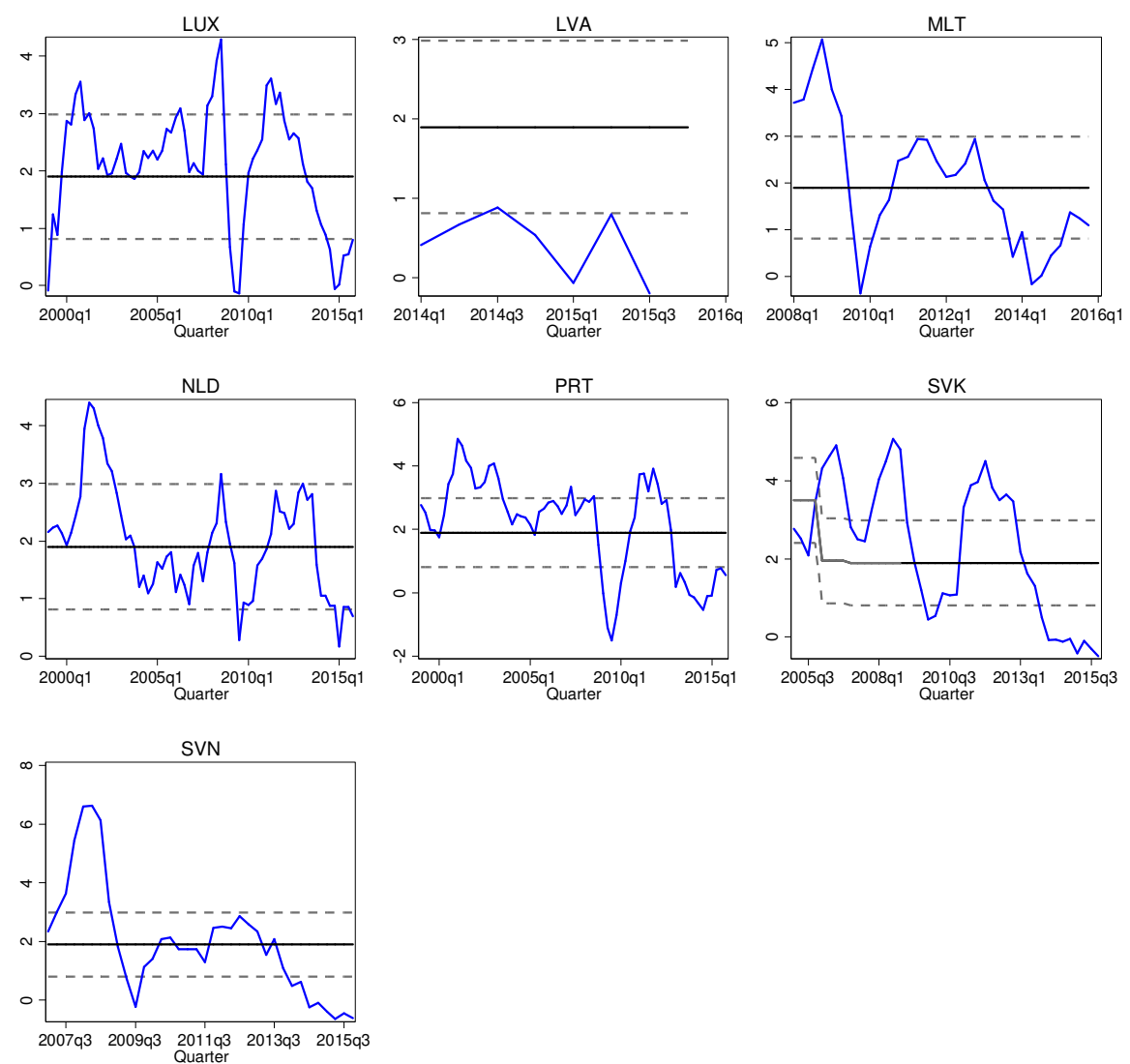

Notes: The plots show the CPI inflation rate in blue jointly with the inflation target rate (solid line) and the target corridor (dotted line) for all inflation targeting countries in the sample that are part of the euro area in 2017. The black color indicates actual data obtained from central bank websites, while the grey color indicates a hypothetical target corridor. We assume a symmetric corridor with a size of $+/-1$ percentage points around the target rate.

Country codes: AUT=Austria, BEL=Belgium, CYP=Cyprus, DEU=Germany, ESP=Spain, EST=Estonia, FIN=Finland, FRA=France, GRC=Greece, IRL=Ireland, ITA=Italy, LTU=Lithuania, LUX=Luxemburg, LVA=Latvia, MLT=Malta, NDL=Netherlands, PRT=Portugal, $\mathrm{SVK}=$ Slovakia, $\mathrm{SVN}=$ Slovenia..

Figure A5: Inflation and targets in non-euro area countries
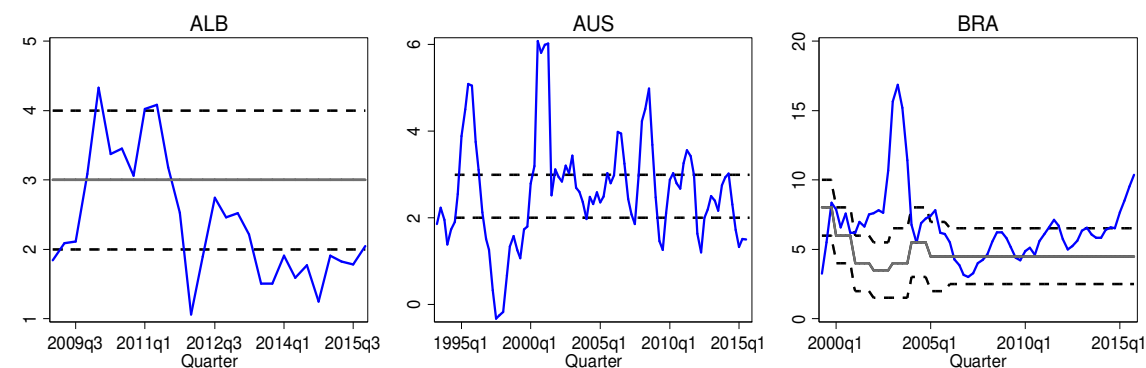

[Continued on next page] 
[Figure A5: Inflation and targets in non-euro area countries] continued
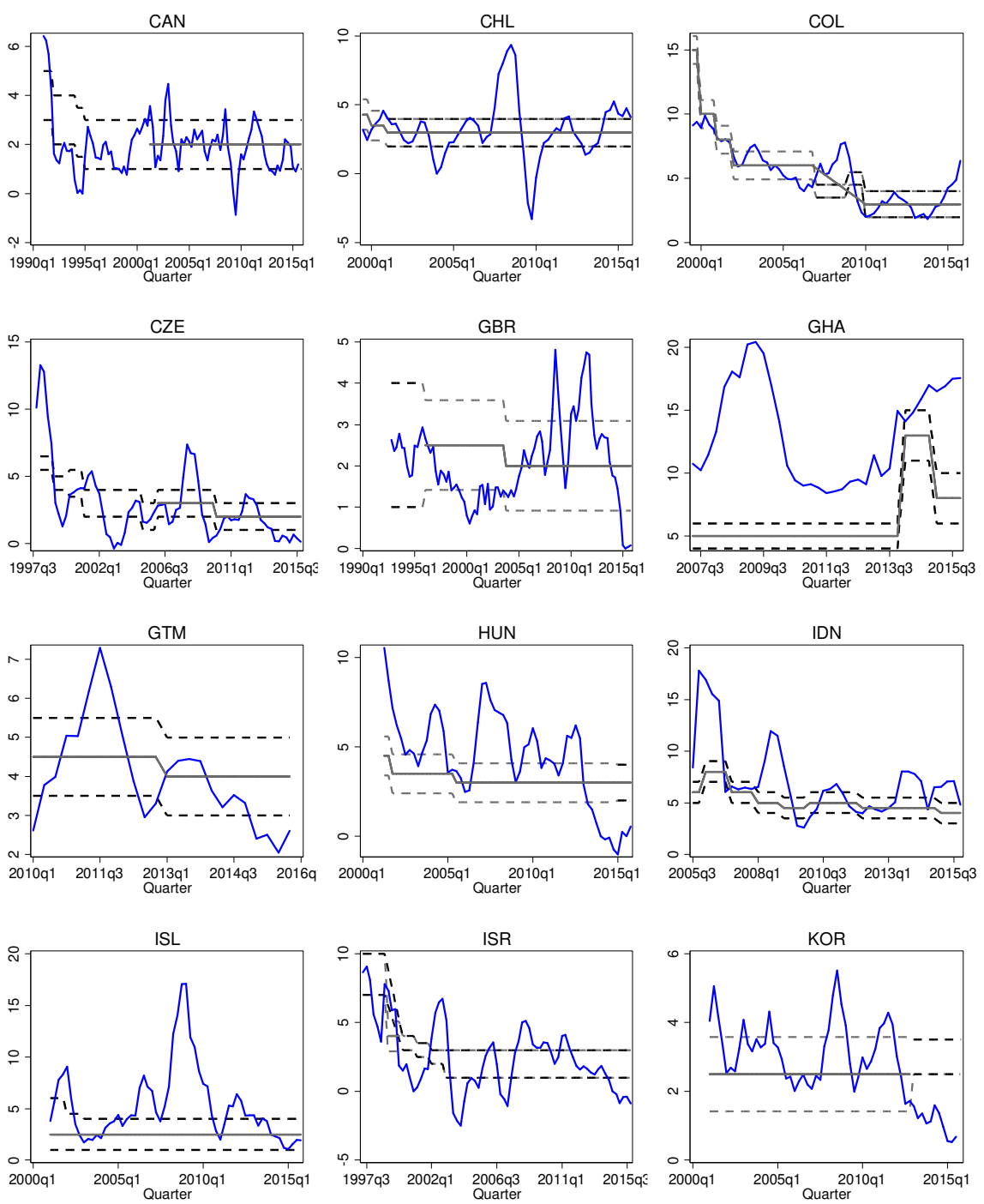

[Continued on next page] 
[Figure A5: Inflation and targets in non-euro area countries] continued
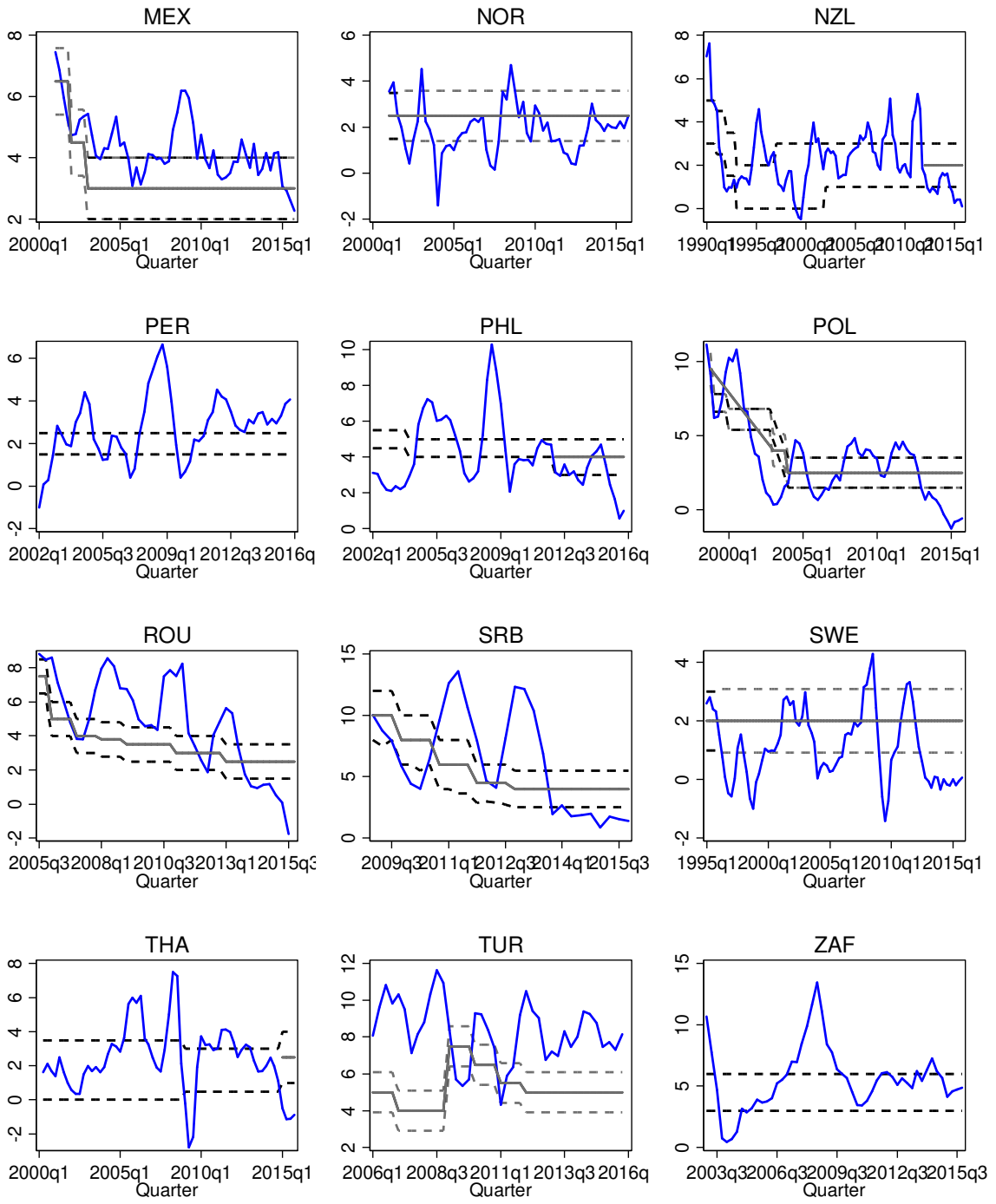

Notes: The plots show the CPI inflation rate in blue jointly with the inflation target rate (solid line) and the target corridor (dotted line) for all inflation targeting countries (non-euro area) in the sample. The black color indicates actual data obtained from central bank websites, while the grey color indicates a hypothetical target corridor. We assume a symmetric corridor with a size of $+/$ - 1 percentage points around the target rate.

Country codes: $\mathrm{ALB}=\mathrm{Albania}, \mathrm{AUS}=\mathrm{Australia}, \mathrm{BRA}=\mathrm{Brazil}, \mathrm{CAN}=\mathrm{Canada}, \mathrm{CHL}=\mathrm{Chile}, \mathrm{COL}=\mathrm{Colombia}, \mathrm{CZE}=\mathrm{Czech}$ Republic, GBR=United Kingdom, GHA=Ghana, GTM=Guatemala, HUN=Hungary, IDN=Indonesia, ISL=Iceland, ISR=Israel, KOR=Korea, MEX=Mexico, NOR=Norway, NZL=New Zealand, PER=Peru, PHL=Philippines, POL=Poland, ROU=Romania, SRB=Serbia, SWE=Sweden, THA=Thailand, TUR=Turkey, ZAF=South Africa.

\section{REFERENCES - ONLINE APPENDIX}

Ball, L. (2010). 'The Performance of Alternative Monetary Regimes', in: Handbook of Monetary Economics, Vol. 3, B.M. Friedman and M. Woodford, Eds: Elsevier. 13031343.

Beck, N. and J. N. Katz (1995). 'What to do (and not to do) with time-series cross-section data', American Political Science Review, Vol. 89(03), 634-647. 
Chinn, M. D. and H. Ito (2008). 'A new measure of financial openness', Journal of Comparative Policy Analysis: Research and Practice, Vo. 10(3), 309-322.

Coibion, O. (2012). 'Are the effects of monetary policy shocks big or small?', American Economic Journal: Macroeconomics, 4(2), 1-32.

Ebeke, C. and A. Fouejieu (2015). 'Inflation Targeting and Exchange Rate Regimes in Emerging Markets', IMF Working Papers, WP/15/228.

Ghosh, A. R., J. D. Ostry and M. Chamon (2016). 'Two targets, two instruments: Monetary and exchange rate policies in emerging market economies', Journal of International Money and Finance, Vol. 60, 172-196.

Ilzetzki, E., C. M. Reinhart and K. S. Rogoff (2017) 'Exchange arrangements entering the 21st century: Which anchor will hold?', NBER Working Paper, No. 23134.

Judson, R. A. and A. L. Owen (1999). 'Estimating dynamic panel data models: A guide for macroeconomists', Economics Letters, 65(1), 9-15.

Kaufmann, D., A. Kraay and M. Mastruzzi (2006). 'Governance matters V: Aggregate and individual governance indicators for 1996-2005', World Bank Policy Reseach Working Paper, No. 4012.

Nickell, S. (1981). 'Biases in Dynamic Models with Fixed Effects', Econometrica, 49(6), 1417-1426.

Roger, S. (2009). 'Inflation Targeting at 20: Achievements and Challenges', IMF Working Papers, WP/09/236.

Romer, C. D. and D. H. Romer (2004). 'A new measure of monetary shocks: Derivation and implications', The American Economic Review, 94(4), 1055-1084.

Rose, A. K. (2014). 'Surprising similarities: recent monetary regimes of small economies', Journal of International Money and Finance, Vol. 49, 5-27.

Schaechter, A., T. Kinda, N. Budina and A. Weber (2012). 'Fiscal rules in response to the crisis-toward the'next-generation'rules: A new dataset', IMF Working Papers, WP/12187.

Shambaugh, J.C. (2004). 'The effect of fixed exchange rates on monetary policy', Quarterly Journal of Economics, 119(1), 301-352. 